\title{
Assessing the effect of a primary health care intervention for improving pre-eclampsia and eclampsia knowledge and practice in Bangladesh
}

\author{
Sharif M.I. Hossain \\ Population Council \\ Shongkour Roy \\ Population Council \\ Kanij Sultana \\ Population Council \\ Charlotte E. Warren \\ Population Council
}

Follow this and additional works at: https://knowledgecommons.popcouncil.org/departments_sbsr-rh

Part of the Demography, Population, and Ecology Commons, Family, Life Course, and Society Commons, International Public Health Commons, Maternal and Child Health Commons, and the Medicine and Health Commons

How does access to this work benefit you? Let us know!

\section{Recommended Citation}

Hossain, Sharif M.I., Shongkour Roy, Kanij Sultana, and Charlotte E. Warren. 2019. "Assessing the effect of a primary health care intervention for improving pre-eclampsia and eclampsia knowledge and practice in Bangladesh," Ending Eclampsia Endline Report. Washington, DC: Population Council. 


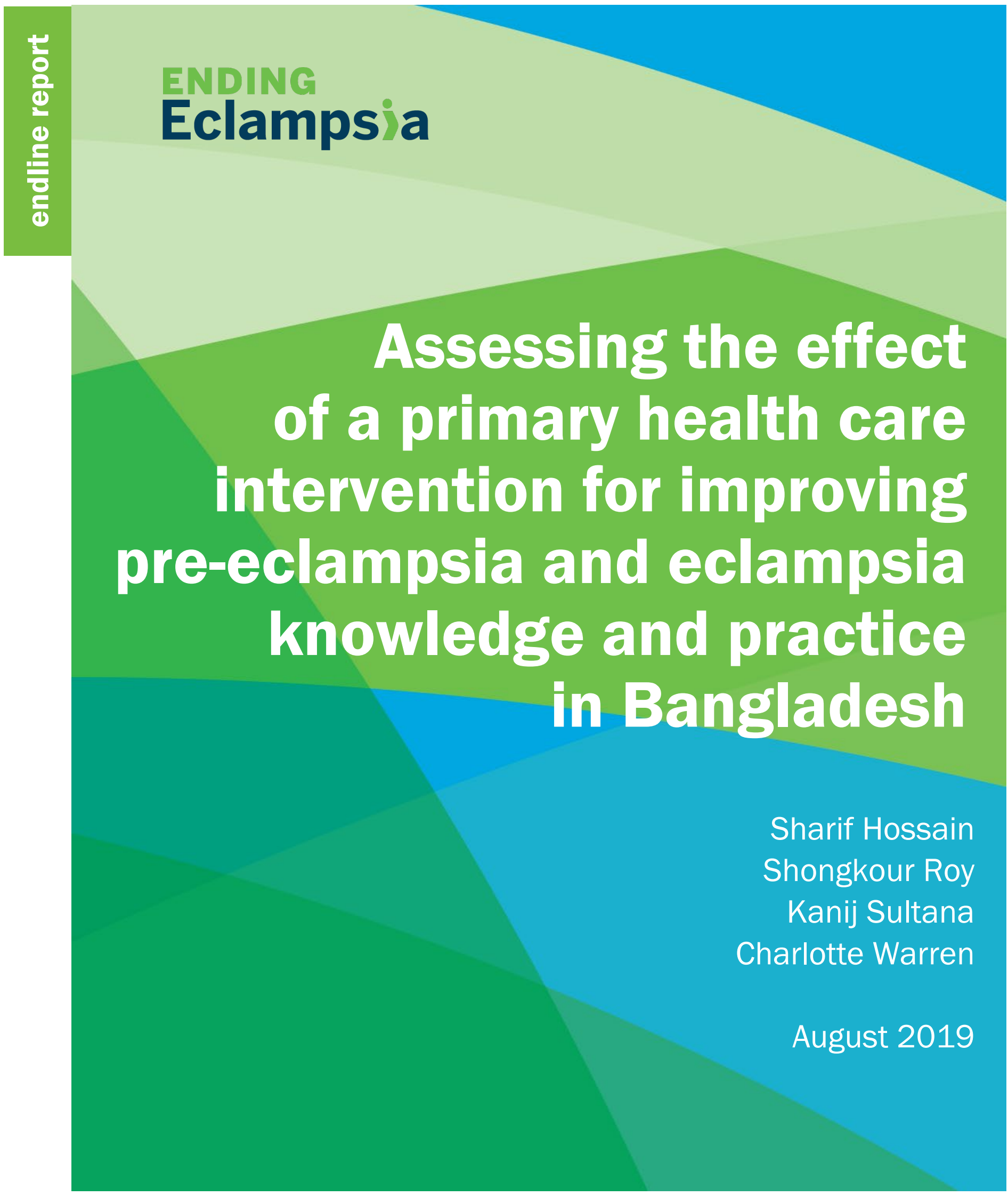




\section{ENDING}

Ending Eclampsia seeks to expand access to proven, under-utilized interventions and commodities for the prevention, early detection, and treatment of pre-eclampsia and eclampsia and strengthen global partnerships.

\section{POPULATION COUNCIL \\ Ideas. Evidence. Impact.}

The Population Council confronts critical health and development issues-from stopping the spread of HIV to improving reproductive health and ensuring that young people lead full and productive lives. Through biomedical, social science, and public health research in 50 countries, we work with our partners to deliver solutions that lead to more effective policies, programs, and technologies that improve lives around the world. Established in 1952 and headquartered in New York, the Council is a non-governmental, non-profit organization governed by an international board of trustees.

\section{Population Council}

4301 Connecticut Avenue NW, Suite 280

Washington, DC 20008

Tel: +1. 8772379400

www.popcouncil.org

Population Council

House 12, Road 25/30

Gulshan 1, Dhaka 1212

Bangladesh

Tel: $+88029842276,9846657$

email: info.bangladesh@popcouncil.org

\section{USAID}

The Ending Eclampsia project is made possible by the generous support of the American people through the United States Agency for International Development (USAID) under the terms of USAID APSOAA-A-14-00048. The contents of this report are the sole responsibility of the Ending Eclampsia project and the Population Council and do not necessarily reflect the views of USAID or the United States Government. 


\section{Table of Contents}

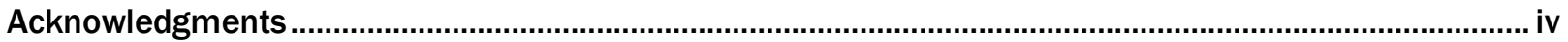

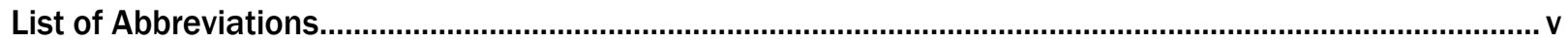

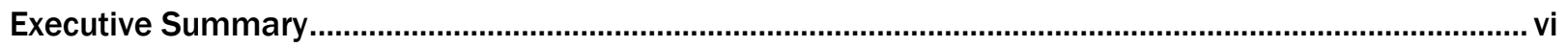

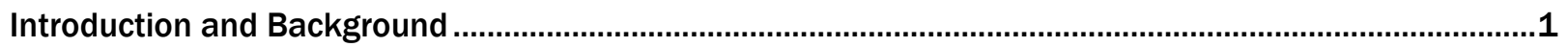

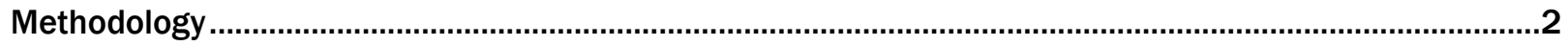

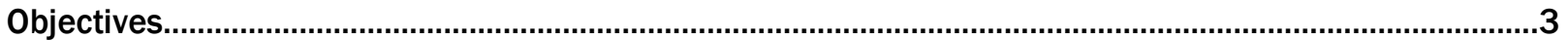

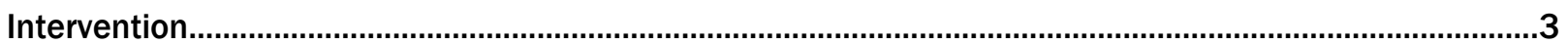

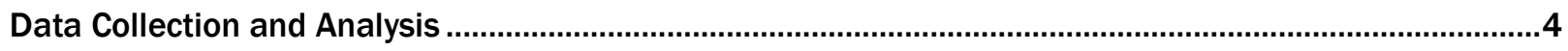

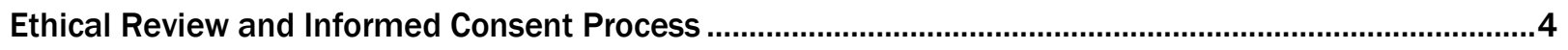

Selection of Implementation Sites ...........................................................................................................

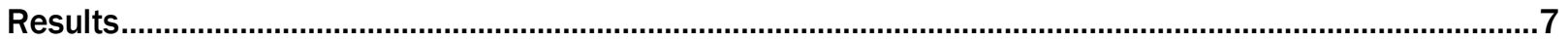

Service Providers' Background Characteristics .................................................................................. 7

Antenatal Care Clients' Background Characteristics..............................................................................8

Policy and Programming for Pre-Eclampsia and Eclampsia ..................................................................

Health System ...........................................................................................................................144

Clients' Experiences at Facilities and Quality of Care .......................................................................244

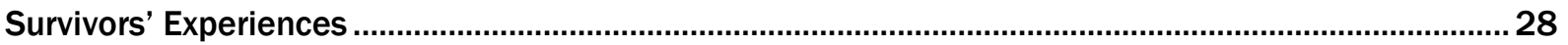

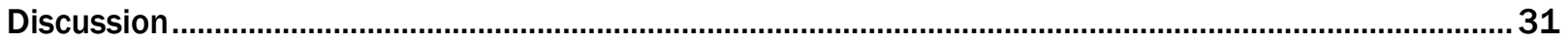

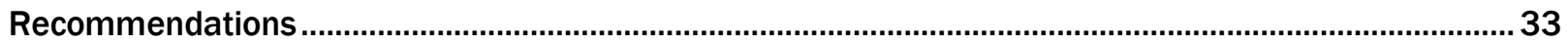

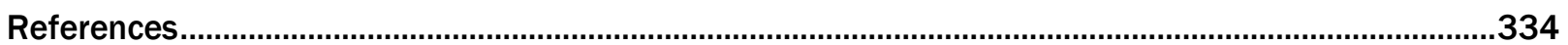

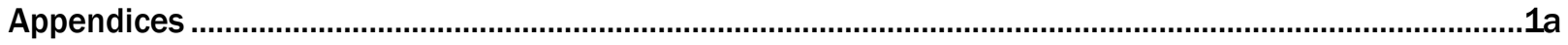




\section{Acknowledgments}

This report was prepared using data collected on the post-intervention findings of pre-eclampsia and eclampsia prevention, detection, and management in Bangladesh, particularly for increasing the use of magnesium sulphate in selected facilities. Intervention scale up and several implementation research (IR) studies were conducted in collaboration with the Directorate General of Family Planning (DGFP) and extended support from Directorate General of Health Services (DGHS) and Obstetric \& Gynecological Society of Bangladesh (OGSB). We would like to express our sincere gratitude to Dr. Kazi Mustafa Sarwar, Director General, DGFP, MoH\&FW for his keen interest in the subject and extending his passionate support.

We are thankful to the United States Agency for International Development (USAID) for their technical and financial support and for providing necessary guidance to complete intervention scale up and implementation research studies. Particular thanks to Ms. Emily Hillman, Dr. Samina Choudhury, and Ms. Edna Jones who have given their continuous guidance and intelligence to complete the studies. We would also like acknowledge MacArthur foundation's supports for part of the studies.

We would also like to express our sincere thanks and gratitude to Dr. Mohammed Sharif, Director (MCHServices) and Line Director MCRAH, DGFP for his leadership and guidance for intervention scale up and completion of implementation research studies. We like to thank Dr. Tapash Ranjan Das, former Deputy Director, $\mathrm{MCH}, \mathrm{MCH}$ Unit, DGFP; Dr. Fahmida Sultana, Deputy Director, MCH services, Dr. Farid Uddin Ahmed, Deputy Director, MCH (RAH), DGFP; Dr ABM Shamsuddin Ahmed, PM (Support Service \& Coordination), MCH Unit, DGFP and Dr Nasima Khatun, Deputy Program Manager (MNCAH), DGHS for their policy and administrative support and cooperation for intervention scale up, completion of implementation research studies, assistance in data collection and monitoring program implementation.

Authors would like to express their sincere thanks to Civil Surgeons (CS) and Deputy Directors of Family Planning (DD-FP), UH\&FPOs, UFPOs and Ob/Gyn consultants of Comilla, Rangpur, Tangail and Bhola districts for their tremendous support during intervention scale up, training, implementation of IR studies, data collection and monitoring. It is the participating service providers who successfully completed the project activities, our salutation to their dedication and we acknowledge their performance.

Regards and thanks are due to all respondents who made their valuable time available to provide interviews. We are indebted and respectful to those mothers who had given their time and patience by providing interviews and provided valuable information. Without their cooperation, the study would not have been possible.

Finally, we appreciate our colleagues at the Population Council who have given their efforts in training, data collection and analysis, and administrative support. 


\section{List of Acronyms}

$\begin{array}{ll}\text { ANC } & \text { Antenatal Care } \\ \text { BDHS } & \text { Bangladesh Demographic and Health Survey } \\ \text { BMMS } & \text { Bangladesh Maternal Mortality Survey } \\ \text { CEmOC } & \text { Comprehensive Emergency Obstetric Care } \\ \text { DGFP } & \text { Directorate General of Family Planning } \\ \text { DGHS } & \text { Directorate General of Health Services } \\ \text { DH } & \text { District Hospital } \\ \text { FP } & \text { Family Planning } \\ \text { FWA } & \text { Family Welfare Assistant } \\ \text { FWV } & \text { Family Welfare Visitor } \\ \text { Ob/Gyn } & \text { Obstetrics and Gynecology } \\ \text { HDP } & \text { Hypertensive Disease of Pregnancy } \\ \text { IDI } & \text { In-Depth Interview } \\ \text { IEC } & \text { Information Education and Communication } \\ \text { MCWC } & \text { Mother and Child Welfare Centre } \\ \text { MgSO } 4 & \text { Magnesium Sulphate } \\ \text { MMR } & \text { Maternal Mortality Ratio } \\ \text { MNH } & \text { Maternal and Newborn Health } \\ \text { MoH } & \text { Ministry of Health } \\ \text { MoH\&FW } & \text { Ministry of Health and Family Welfare } \\ \text { NGO } & \text { Non-Governmental Organization } \\ \text { OGSB } & \text { Obstetrical and Gynecological Society of Bangladesh } \\ \text { PE/E } & \text { Pre-Eclampsia/Eclampsia } \\ \text { PHC } & \text { Primary Health Care } \\ \text { PNC } & \text { Postnatal Care } \\ \text { RH } & \text { Reproductive Health } \\ \text { SACMO } & \text { Sub-Assistant Community Medical Officer } \\ \text { SPE } & \text { Severe Pre-Eclampsia } \\ \text { UH\&FWC } & \text { Union Health and Family Welfare Centre } \\ \text { UHC } & \text { Upazila Health Complex } \\ \text { USAID } & \text { United States Agency for International Development } \\ & \\ \text { HM } & \end{array}$




\section{Executive Summary}

In Bangladesh, 24 percent of maternal deaths are due to pre-eclampsia and eclampsia (PE/E)-and nearly all of these deaths are preventable. With a mission to focus attention and efforts on $P E / E$, the Ending Eclampsia project scaled up PE/E early detection, prevention, and management in 136 primary health care $(\mathrm{PHC})$ facilities in Bangladesh, including 20 referral facilities, for over 24 months to assess effectiveness and acceptability of under-utilized strategies and commodities to reduce morbidities and mortalities of mothers and their babies. This intervention included training on hypertension during pregnancy and $\mathrm{PE} / \mathrm{E}$, refresher training after three months, and guaranteeing availability of commodities and supplies including magnesium sulphate $\left(\mathrm{MgSO}_{4}\right)$ for intramuscular injections, urine dipsticks, syringes and needles, functioning sphygmomanometer and stethoscope, along with a service delivery protocol for PHC providers. This pre-post, cross-sectional research design integrated both qualitative and quantitative data collection methods at baseline (2015) and endline (2018).

This intervention, targeting PHC facilities, has resulted in a number of notable successes. A national service delivery protocol for PHC service providers' administration of $\mathrm{MgSO}_{4}$ with referrals was adopted, followed by the incorporation of PE/E instruction in PHC providers' basic curricula, and its inclusion in the government's operation plan for 2017 through 2022, which includes a $\mathrm{MgSO}_{4}$ procurement plan. There is evidence of improved PHC provider knowledge, abilities, and practices for detecting, preventing, and managing $P E / E$, improved facility readiness to provide $P E / E$ services, improved quality of care, and increased $\mathrm{PE} / \mathrm{E}$ detection and administration of $\mathrm{MgSO}_{4}$, all with minimum poor outcomes.

Assessments of facility readiness show significant improvements from baseline to endline in availability and functionality of PE/E commodities and supplies in the intervention facilities, particularly blood pressure (BP) machines, stethoscopes, urine dipsticks, $\mathrm{MgSO}_{4}$, as well as the service delivery protocol for diagnosis and management of $\mathrm{PE}$, severe $\mathrm{PE}$, and eclampsia (PE/SPE/E). Correct knowledge on hypertensive disorders, particularly during pregnancy, including $\mathrm{PE} / \mathrm{SPE} / \mathrm{E}$, significantly improved at endline compared to baseline. Similarly, service providers' diagnostic abilities for SPE/E significantly improved at endline-except for chronic hypertension. There was also fourteen-fold increase in knowledge of the loading dose of $\mathrm{MgSO}_{4}$ from baseline. All of these findings indicate positive impacts on provider knowledge, competence, and facility readiness.

Provider practice of $\mathrm{PE} / \mathrm{E}$ detection and management significantly improved at endline. Similarly, provider administration of a loading dose of $\mathrm{MgSO}_{4}$ significantly increased from baseline (12\%) to endline (48\%). The quality of antenatal care (ANC) significantly improved as well. No maternal deaths were recorded among those who received a $\mathrm{MgSO}_{4}$ loading dose during $\mathrm{PHC}$. These findings are extraordinarily positive changes, particularly because PHC facilities had no procedures for PE/E detection, prevention, or management prior to the intervention.

A few areas could benefit from more attention. At endline some patients, albeit a small proportion, with severe PE/E (SPE) were not given $\mathrm{MgSO}_{4}$ or refused it. Additionally, the detection rate of hypertensive disease in pregnancy (HDP) was still low at endline, which indicates more efforts needed to motivate service providers for consistent, correct BP measurement and urine testing for albumin during ANC visits.

Finally, significant improvement in screening pregnant women for high risk factors during ANC, diagnosis of $\mathrm{PE} / \mathrm{E}$ among $\mathrm{ANC}$ and postnatal care (PNC) patients, uptake of PE/E services over 24 months, and use of $\mathrm{MgSO}_{4}$ in case of SPE/E at endline are considered as contributions of our implementation of PHC PE/E model. Policymakers and program managers, service providers, and other stakeholders strongly advocate for the scale up of this intervention in other parts of the country, for SDG achievement. 


\section{Background}

Globally, approximately 830 women die every day from preventable complications related to pregnancy or childbirth, and 7,300 women experience a stillbirth (World Health Organization 2018; WHO, UNICEF, UNFPA, World Bank, United Nations Population Division 2015; Lancet 2016). Around 10 percent of women experience hypertensive disease of pregnancy (HDP) (Duley et al 2009, Steegers et al 2010). Among them, four to five percent present as pre-eclampsia (PE) (Steegers et al 2010, Abalos et al 2013, Arulkumaran et al 2013), defined as hypertension with proteinuria after 20 weeks gestation. In low- and middle income countries (LMIC), a woman is seven times more likely to develop PE than a woman in a high income country; between 10 and 25 percent of these cases will result in maternal death (WHO 2007).

Although the rates of stillbirths have fallen since year 2000, approximately 2.6 million babies globally were stillborn in 2015 , or around 7,400 every day. Nearly half were intrapartum stillbirths that are preventable with high quality care at birth and early identification of at-risk pregnancies (Lancet 2016). In Bangladesh, the risk of dying in the first month of life (neonatal mortality) is 30 per 1,000 live births, accounting for 67 percent of all under-five deaths (BDHS 2018).

The Bangladesh Maternal Mortality Survey (BMMS) 2017 revealed that the maternal mortality ratio (MMR) remained unchanged, at 196 per 100,000 live births since 2010. Eclampsia remains the second leading direct cause of maternal deaths, having increased from 20 percent to 24 percent, after postpartum hemorrhage (PPH) (31\%): These two causes are responsible for more than half of maternal deaths (54\%) (NIPORT 2017) in Bangladesh. Among the 5,000 to 6,000 maternal deaths each year in the country, 1,000 to 1,200 mothers die from eclampsia. Risk of maternal death is high among first-time mothers (215 per 100,000 live births) as well as those with parities of four or higher. The pregnancy-related mortality ratio (PRMR) among the youngest women (15 to 19 years) is 144 deaths per 100,000 live births, compared to 2,031 per 100,000 live births among women ages 45 to 49 (NIPORT 20117).

In resource-poor countries such as in Bangladesh, proven life-saving commodities for pregnant women have not been optimally examined, such as magnesium sulphate $\left(\mathrm{MgSO}_{4}\right)$ to manage SPE/E, use of antihypertensives to manage high blood pressure (BP) during pregnancy, aspirin prophylaxis for pregnant women at high risk of $\mathrm{PE} / \mathrm{E}$, as well as task shifting to lower health worker cadres, and community involvement. Hodgins et al. conclude that simple interventions during pregnancy, such as PE/E detection, have considerable potential impacts on important mortality outcomes; they found that reliable PE detection followed by timely delivery could prevent up to one fourth of newborn and stillbirth deaths, and over 90 percent of maternal PE/E deaths (2018). There has been no systematic review of research and programming on PE/E prevention, early detection, and treatment in Bangladesh. Until recently, PE/E policies, health structures, and community perceptions were largely unknown to program implementers or service providers.

With support from USAID, the Ending Eclampsia project has been expanding access to proven, underutilized interventions and commodities for PE/E prevention, early detection, and management, particularly expansion of $\mathrm{MgSO}_{4}$ access in several countries through primary health care (PHC) providers and strengthening global collaboration and partnerships. In 2015, a landscaping analysis including a systematic literature review (available at endingeclampsia.org) identified articles reporting PE/E burdens, common risk factors, incidence, adverse outcomes, and mortality rates; few studies, however, discuss implementation research (IR) for improving PE/E prevention, detection, and timely management, particularly within PHC facilities (Warren at al 2016). Following a two year intervention expanding $\mathrm{MgSO}_{4}$ provision through $\mathrm{PHC}$ providers in 12 sub-districts of Bangladesh, and subsequent data collection, the following report describes this IR by the Population Council, from 2015 to 2018. 


\section{Methodology}

This pre-post, cross-sectional study, with both qualitative and quantitative data collection methods at baseline (2015) and endline (2018), collected data at various levels of PHC in Bangladesh-at Union Health and Family Planning Centres (UH\&FWCs), referral facilities or where comprehensive emergency obstetric and newborn care (CEmONC) is available including Upazila Health Complexes (UHCs), District Hospitals (DHs), Mother and Child Welfare Centers (MCWCs), and ANC units of two medical college and hospitals (Tangail and Rangpur). The total number of facilities included in the study is 136-at 116 UH\&FWCs, 11 UHs, five MCWCs, two DHs, and two medical college and hospitals.

Respondents were selected from 12 sub-districts in four districts selected for intervention scale up and IR studies. Almost all facilities were the same in pre- and post-data collection, except two that were added in post-intervention data collection. The primary sampling unit was a health care facility, with data collected at endline from posted, trained, re-trained, and mentored service providers. It is possible, at endline, that some service providers, program managers, and policymakers were not the same as those initially surveyed, at baseline, due to transfers or new postings. Newly posted providers were duly trained on the intervention. A separate sample of client-provider interactions (CPIs), ANC exit client interviews, and PE/E survivors were chosen for pre- and post-landscaping analysis. Service use was recorded from all 136 facilities for 24 months and three months before the intervention.

Policy and program data were collected at national, district, and lower levels, in interviews with policymakers, program managers of maternal and newborn health $(\mathrm{MNH})$ programs, and representatives of related local and international NGOs and development partners, to assess policy, programming, and informed opinions of them. Facility assessments, interviews with service providers who work in ANC, maternity, or labor and delivery wards, client observations of ANC CPIs, and exit interviews with pregnant women all aided assessment of facility readiness and service provider knowledge and practice for PE/E detection and management, and their quality of care. All PE/E survivors were followed up, monitored, and interviewed to assess their care experiences at these facilities, along with the outcomes of their pregnancies. Monitoring service use and other related project indicators were collected monthly, over 24 months, to determine changes in service uptake and project management indicators.

One IR study (detailed in a separate report) assessed capacity of PHC providers (in a sub-set of facilities) to prescribe an oral anti-hypertensive drug to pregnant women and refer them for follow up care. Another study followed a cohort of women and their babies who experienced PE/E, to assess postnatal quality of care and health outcomes (detailed in a separate report).

TABLE 1 Data collection for landscaping analysis, by district, $n$

\begin{tabular}{|c|c|c|c|c|c|c|c|c|c|c|}
\hline \multirow{2}{*}{ Data types } & \multicolumn{2}{|c|}{ Comilla } & \multicolumn{2}{|c|}{ Rangpur } & \multicolumn{2}{|c|}{ Tangail } & \multicolumn{2}{|c|}{ Bhola } & \multicolumn{2}{|c|}{ Total } \\
\hline & $\mathrm{BL}$ & EL & $\mathrm{BL}$ & EL & BL & EL & $\mathrm{BL}$ & EL & BL & EL \\
\hline Facility inventory & 41 & 41 & 32 & 34 & 31 & 30 & 30 & 31 & 134 & 136 \\
\hline Service provider interview & 92 & 88 & 68 & 80 & 80 & 89 & 49 & 71 & 289 & 328 \\
\hline Client provider interaction & 82 & 10 & 63 & 84 & 63 & 89 & 60 & 80 & 268 & 353 \\
\hline ANC client exit interview & 24 & 26 & 17 & 21 & 18 & 20 & 16 & 20 & 768 & 888 \\
\hline IDIs-eclampsia survivors & - & 58 & - & 49 & - & 57 & - & 43 & 22* & 50 \\
\hline IDIs-policymakers, program managers & 10 & 8 & 9 & 8 & 9 & 7 & 6 & 5 & $50 * *$ & $36 * * *$ \\
\hline Monitoring data & \multicolumn{10}{|c|}{ Monthly service uptake data from 136 facilities, for 24 months } \\
\hline
\end{tabular}




\section{Objectives}

This post-intervention assessment sought to compare any changes in policy, the health system, and community facilities following a two year intervention. Endline data collection had several objectives:

- Identifying the views and opinions of policymakers, program managers, and other stakeholders of $\mathrm{PE} / \mathrm{E}$ detection, prevention, and management, and a loading $\mathrm{MgSO}_{4}$ dose, during the course of the intervention period in Bangladesh;

- Identifying health system improvements, as well as impediments within the health system, in selected facilities for PE/E detection, prevention, and management;

- Assessing service providers' knowledge and practices, changes in their quality of care, and knowledge of ANC clients attending intervention facilities;

- Assessing the views and experiences of PE/E survivors administered $\mathrm{MgSO}_{4}$ injections at their community (i.e. PHC) facilities; and

- Investigating uptake of services and changes in project indicators.

\section{Intervention}

In expanding services to prevent, detect, and manage PE/E, the core intervention in Bangladesh included training for PHC providers-Family Welfare Visitors (FWVs) and Sub-Assistant Community Medical Officers (SACMOs)-along with nurses or midwives in ANC units, in addition to ongoing mentorship for identifying $\mathrm{PE} / \mathrm{E}$ signs and symptoms, administering a modified loading dose of $\mathrm{MgSO}_{4}$ where needed, and referring pregnant women to referral facilities for further PE/E management. This intervention followed the PHC/PE model:
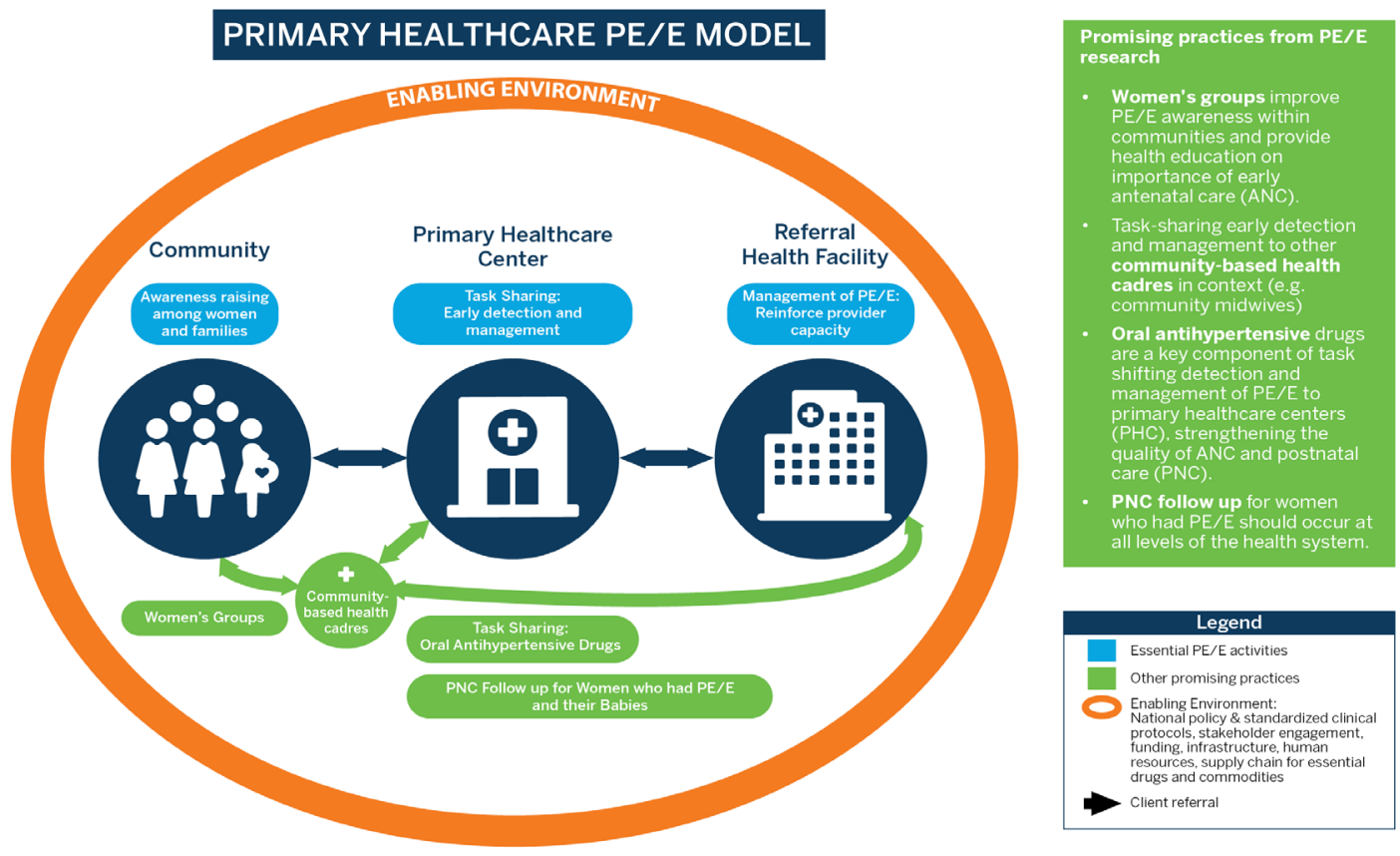
The PHC PE/E Model was implemented at policy, health system (referral and PHC), and community levels. An enabling policy environment was facilitated by the Project Advisory Committee (PAC) formed in cooperation with the Director of MCH Services and Line Director (MCRAH) of the Directorate General of FP (DGFP), which advised and guided implementation, and collaborated on a PE/E service delivery protocol for $\mathrm{PHC}$ providers (including the $\mathrm{MgSO}_{4}$ loading dose), complemented by a job aid or algorithm for diagnosis and management of hypertension and PE/E and a pamphlet for clients. The project focused on institutionalizing PE/E within PHC providers' basic training curricula, as well as its incorporation in DGFP's operation plan. All service providers at intervention facilities were trained and re-trained on hypertension, $\mathrm{PE} / \mathrm{E}$, dipstick tests, $\mathrm{BP}$ measurement, referrals, and $\mathrm{MgSO}_{4}$ administration. In addition, equipment (e.g. BP machines, stethoscopes, dipsticks for urine albumin test, patella hammers, etc.) and commodities (for $\mathrm{MgSO}_{4}$ injection) were made available where needed. Field workers were trained on PE/E and pamphlet distribution. Community activities were limited to PHC provider and field worker distribution of client pamphlets, within facilities and communities, respectively.

Training covered PE/E's theoretical and practical elements, including BP measurement, urine analysis (with dipstick), $\mathrm{MgSO}_{4}$ injection, risk factors of pregnant women, client follow up, recording, and referral. Service providers were first trained for two days, with a one day refresher after three months. Referral facility providers were trained on $\mathrm{PE} / \mathrm{E}$, mentorship, and patient management after a loading dose of $\mathrm{MgSO}_{4}$.

The intervention was implemented for 24 months. A total of 51 doctors were trained for their subsequent training of 399 PHC providers (FWVs, SACMOs and nurses) and 591 field workers from 12 sub-districts of four districts. Although SACMOs do not see ANC patients, they were trained to support FWVs. In addition, 94 program managers from the four districts were trained prior to the intervention, and 52 during refresher training. A refresher training with $217 \mathrm{PHC}$ providers three months after the initial training allowed them to share their experiences and resolve any emerging issues.

A district monitoring officer visited each facility every month. Central Directorate staff provided mentoring, in addition to the local program manager, every quarter. The intervention included educational efforts only at facilities, with service providers and field workers distributing a PE/E brochure to clients. No intervention was implemented within the communities.

\section{Ethical Review and Informed Consent Process}

The study protocol was reviewed and approved by Population Council's Institutional Review Board (IRB) in New York. The protocol, informed consent forms, and tools were also reviewed by Bangladesh Medical

Research Council (BMRC)'s Ethics Committee. Participation in the study was voluntary, and informed consent was received from all participants before interviews.

\section{Data Collection and Analysis}

Prior to study implementation, approval and administrative orders were received from both DGFP and the Directorate General of Health Services (DGHS). A 33-member data collection team, including six supervisors, were recruited and trained for 10 days, on the study's objectives, its tools, procedures, and ethical conduct of data collection. All researchers were trained on data collection in the field for one, outside the study area. Four groups, each with five data collectors and one supervisor, were assembled for quantitative data collection, with two groups, each with four interviewers and one supervisor, were assembled for qualitative data collection. 
All service providers who participated in the training were selected for an interview. Some service providers, program managers, or policymakers interviewed initially may not have been interviewed at endline due to transfers or new postings. A separate sample of CPIs, ANC exit client interviews, and PE/E survivors were chosen for pre- and post-landscaping analysis. Facility assessments were at the same facilities pre- and post-intervention. Monitoring of service uptake and other related project indicators was monthly, for 24 months, to accurately determine any changes.

Completed questionnaires were checked by supervisors in the field and sent to the Council's office for editing, entry, and analysis. Quantitative data were edited, coded, entered, and analyzed using STATA/SAS software. Data entry utilized CSPro, with double entries to minimize errors. Descriptive, bivariate, and comparative analyses (chi-Square test, Fisher's Exact test, Wilcoxon Rank-Sum Statistic) were performed, with results are presented in this report as frequencies and percentages. In few cases, aggregated scores were generated in STATA to measure multi-element constructs such as "Assessing Risk of PE/E". Twentyfour months of service statistics described service uptake and other project-related indicators (particularly PMP indicators). Qualitative interviews were recorded through written notes and audio recordings, then transcribed and translated into English. As with baseline data, thematic coding of endline data and allowed for comparisons over time. Content and thematic analysis used NVivo software, applying a grounded theory approach at baseline and endline, and findings were triangulated by thematic areas.

This report presents its findings within three broad, inter-related domains: Policy, Health System, and Community (Figure 1). The policy domain includes policy on PE/E detection, prevention, and management, $\mathrm{MgSO}_{4}$ administration by PHC providers, and stakeholder views and support for task sharing. The health system comprises service provider knowledge and practices of PE/E management, HDP, skills in BP measurement and urine analysis for albumin, logistics and commodity availability for PE/E management, service uptake, program impact, and service quality. Community perspectives include ANC clients' perceptions and understanding of PE/E and pregnancy danger signs, experiences at facilities, and PE/E survivors' experiences in receiving care.

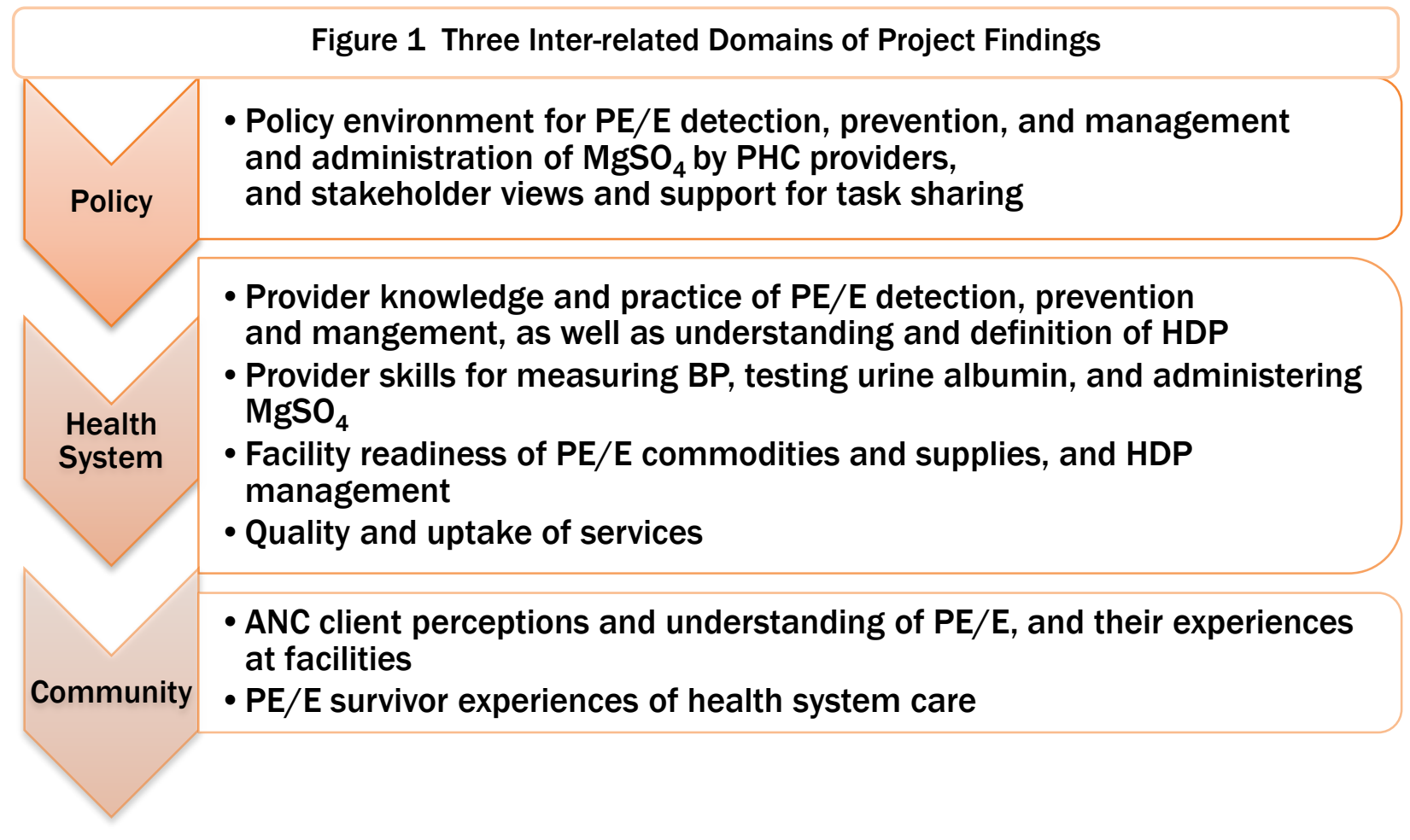




\section{Selection of Implementation Sites}

Before the study commenced in 2015, a Memorandum of Understanding (MoU) was signed with the Directorate General of Family Planning (DGFP), Obstetrical and Gynecological Society of Bangladesh (OGSB) and Population Council to work together and a Project Advisory Committee (PAC) was formed to review and advise on the project progress. Ending Eclampsia implementation districts have been selected by the DGFP considering Country's geographical and divisional (administrative) distribution. Bangladesh is a homogenous country in terms of language, education, and health facility. The functional administrative structure is identical from divisional level to union level including health and family planning (FP) services. One district, Bhola, is situated in the south, while another, Rangpur, is in the north. The remaining two districts, Tangail and Comilla, are in the central part of the country. All of the districts are in different administrative areas. Three sub-districts from each district were selected for the intervention, and the baseline and endline surveys.

\section{FIGURE 2 Study districts in Bangladesh}

Districts \& Upazilas:

Rangpur: Kaunia, Gangachara \& Pirganj

Tangail: Kalihati, Madhupur \& Bashail

Comilla: Daudkandi, Burichong \& Debidwar

Bhola: Borhanuddin, Sadar \& Daulatkhan

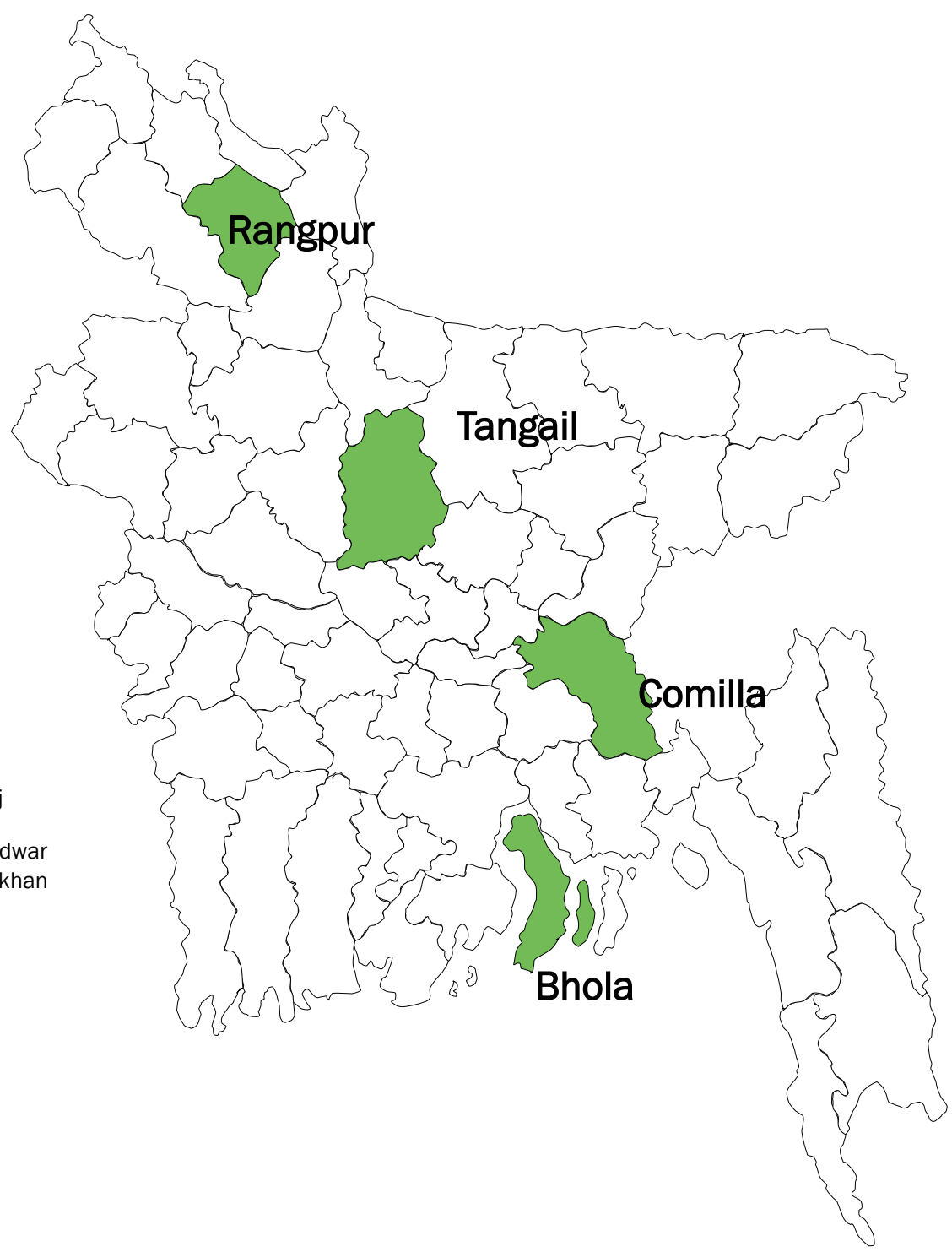




\section{Results}

\section{Service Providers' Background Characteristics}

The service providers who participated in the study were primarily women, with a greater proportion at endline $(p<0.001)$. Approximately two thirds were 40 years of age or older. At baseline most providers were FWVs and SACMOS, while at endline the majority were FWVs and nurses. More referral facility providers, compared to PHC providers, were represented at endline. $(p<0.001)$. At baseline, half of service providers had received training on FP or maternal, newborn and child health (MNCH) within the past three years, compared to all service providers at endline having such training $(p<0.001)$.

TABLE 2 Service providers' background characteristics

\begin{tabular}{|c|c|c|c|c|c|c|}
\hline \multirow{2}{*}{\multicolumn{2}{|c|}{ Background Characteristics }} & \multicolumn{2}{|c|}{ Baseline $(n=289)$} & \multicolumn{2}{|c|}{ Endline $(n=328)$} & \multirow{4}{*}{$\begin{array}{r}\text { p- value } \\
<0.001\end{array}$} \\
\hline & & $n$ & $\%$ & $\mathrm{n}$ & $\%$ & \\
\hline \multirow{2}{*}{ Sex } & Male & 107 & 37.0 & 63 & 19.0 & \\
\hline & Female & 182 & 63.0 & 265 & 81.0 & \\
\hline \multirow{4}{*}{ Age (years) } & $<30$ & 44 & 15.0 & 42 & 13.0 & \multirow{4}{*}{0.20} \\
\hline & $30-39$ & 42 & 15.0 & 68 & 21.0 & \\
\hline & $40-49$ & 104 & 36.0 & 105 & 32.0 & \\
\hline & $>49$ & 99 & 34.0 & 113 & 34.0 & \\
\hline \multirow{2}{*}{ Type of facility } & PHC & 187 & 65.0 & 143 & 44.0 & \multirow{2}{*}{$<0.001$} \\
\hline & Referral & 102 & 35.0 & 185 & 56.0 & \\
\hline \multirow{4}{*}{$\begin{array}{l}\text { Duration of work in ward } \\
\text { or unit (year) }\end{array}$} & $<1$ & 9 & 3.0 & 16 & 5.0 & \multirow{4}{*}{$<0.001$} \\
\hline & $1-5$ & 73 & 25.0 & 113 & 34.0 & \\
\hline & $6-10$ & 16 & 6.0 & 75 & 23.0 & \\
\hline & $>10$ & 191 & 66.0 & 124 & 38.0 & \\
\hline \multirow{4}{*}{ Type of provider } & $\begin{array}{l}\text { MO Clinic/MOMCH/ } \\
\text { MO/Ob/Gyn specialist }\end{array}$ & 72 & 25.0 & 22 & 7.0 & \multirow{4}{*}{$<0.001$} \\
\hline & Nurse & 14 & 5.0 & 111 & 34.0 & \\
\hline & SACMO & 75 & 26.0 & 79 & 24.0 & \\
\hline & FWV & 128 & 44.0 & 116 & 35.0 & \\
\hline \multirow{2}{*}{$\begin{array}{l}\text { Training in FP, MNCH } \\
\text { in last three years }\end{array}$} & Yes & 144 & 49.8 & 328 & 100.0 & \multirow{2}{*}{$<0.001^{b}$} \\
\hline & No & 145 & 50.2 & 0 & 0.0 & \\
\hline \multicolumn{7}{|l|}{ Type of training received ** } \\
\hline & EmOC & 33 & 11.0 & 85 & 26.0 & $<0.001$ \\
\hline & ANC & 38 & 13.0 & 80 & 24.0 & $<0.001$ \\
\hline & Safe delivery care & 35 & 12.0 & 48 & 15.0 & 0.36 \\
\hline & PNC & 36 & 13.0 & 71 & 22.0 & 0.003 \\
\hline Skille & Birth Attendant training & 12 & 4.0 & 21 & 6.0 & 0.22 \\
\hline & Family planning & 60 & 21.0 & 90 & 27.0 & 0.05 \\
\hline & aboratory investigations & 1 & 0.4 & 8 & 2.0 & $0.04^{b}$ \\
\hline Emerge & cy newborn/child health & - & - & 146 & 45.0 & - \\
\hline & $\mathrm{PE} / \mathrm{E}$ & - & - & 328 & 100 & - \\
\hline
\end{tabular}




\section{Antenatal Care Clients' Background Characteristics}

A separate sample of clients exiting facilities immediately after ANC were surveyed at baseline $(n=768)$ and endline $(n=888)$. All women interviewed were married. In both baseline and endline surveys, about one quarter of women were younger than 20 years old, while slightly more than half were 20 to 29 years of age, and the rest were 30 years old or older. More than half of the women had a secondary education, at both baseline and endline, and a majority were Muslim. Most pregnant women interviewed were of more than 20 weeks gestation. Most women were attending at least a second ANC visit. Significant differences were observed for all background characteristics between baseline and endline among women who were interviewed.

TABLE 3 Background characteristics of ANC exit clients, at baseline and endline

\begin{tabular}{|c|c|c|c|c|c|}
\hline \multirow[t]{2}{*}{ Background Characteristics } & \multicolumn{2}{|c|}{$\begin{array}{l}\text { Baseline } \\
(n=768)\end{array}$} & \multicolumn{2}{|c|}{$\begin{array}{l}\text { Endline } \\
(n=888)\end{array}$} & \multirow[t]{2}{*}{$p$-value ${ }^{a}$} \\
\hline & $n$ & $\%$ & $\mathrm{n}$ & $\%$ & \\
\hline \multicolumn{6}{|l|}{ Age (years) } \\
\hline$<20$ & 157 & 20.0 & 221 & 25.0 & \multirow{4}{*}{0.01} \\
\hline $20-24$ & 274 & 36.0 & 277 & 31.0 & \\
\hline $25-29$ & 227 & 30.0 & 231 & 26.0 & \\
\hline$>29$ & 110 & 14.0 & 159 & 18.0 & \\
\hline \multicolumn{6}{|l|}{ Education } \\
\hline Never attended school & 47 & 6.0 & 33 & 4.0 & \multirow{4}{*}{0.004} \\
\hline $\begin{array}{r}\text { Primary } \\
\end{array}$ & 237 & 31.0 & 231 & 26.0 & \\
\hline Secondary & 395 & 51.0 & 488 & 55.0 & \\
\hline Higher secondary and above & 89 & 12.0 & 136 & 15.0 & \\
\hline \multicolumn{6}{|l|}{ Religion } \\
\hline Islam & 720 & 94.0 & 851 & 96.0 & \multirow{2}{*}{0.06} \\
\hline Hinduism & 48 & 6.0 & 37 & 4.0 & \\
\hline \multicolumn{6}{|l|}{ Gestational age at interview (week) } \\
\hline$<13$ & 52 & 7.0 & 83 & 9.0 & \multirow{4}{*}{0.02} \\
\hline $13-20$ & 240 & 31.0 & 229 & 26.0 & \\
\hline 21-28 & 281 & 37.0 & 319 & 36.0 & \\
\hline$>28$ & 195 & 25.0 & 257 & 29.0 & \\
\hline \multicolumn{6}{|l|}{ Location of ANC facility } \\
\hline Referral & 118 & 15.0 & 187 & 21.0 & \multirow{2}{*}{0.003} \\
\hline Primary & 650 & 85.0 & 701 & 79.0 & \\
\hline \multicolumn{6}{|l|}{ Number of current ANC visit } \\
\hline 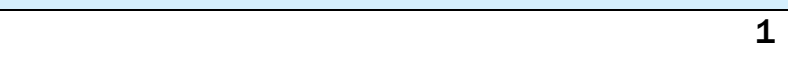 & 282 & 37.0 & 257 & 29.0 & \multirow{4}{*}{$<0.001$} \\
\hline 2 & 236 & 31.0 & 259 & 29.0 & \\
\hline 3 & 147 & 19.0 & 172 & 19.0 & \\
\hline$>=4$ & 103 & 13.0 & 200 & 23.0 & \\
\hline \multicolumn{6}{|l|}{ Socio-economic status } \\
\hline Lower tercile & 318 & 41.0 & 276 & 31.0 & \multirow{3}{*}{$<0.001$} \\
\hline Middle tercile & 281 & 37.0 & 254 & 29.0 & \\
\hline Upper tercile & 169 & 22.0 & 358 & 40.0 & \\
\hline
\end{tabular}




\section{Policy and Programming for Pre-Eclampsia and Eclampsia}

Researchers conducted in-depth interviews (IDIs) with policy stakeholders-including policymakers, program managers from the four districts, and development partners, professionals and implementers, as well as other stakeholders-at baseline $(n=50)$ and endline $(n=37)$, to identify the policy environment and explore stakeholders' perspectives of relevant issues during the implementation period.

\section{Pre-Eclampsia Policy}

The government's PE/E policy falls under the broader public health domain of maternal health. The government's standard operating procedure (SOP) specifies $\mathrm{PE} / \mathrm{E}$ prevention and

\section{$\mathrm{PE} / \mathrm{E}$ polices are within the larger} maternal health domain management at secondary and tertiary health system levels. The government has yet to formalize any policy for $\mathrm{PE} / \mathrm{E}$ prevention and management at primary $(\mathrm{PHC})$ and community levels of care.

A service delivery protocol, the Service Delivery Protocol for PE/E for PHC Providers, was developed, tested, and approved by the DGFP for implementation in Ending Eclampsia and MaMoni project districts.

Varied perceptions and confusion were observed among informants when discussing the existence of a national PE/E policy. While most central policy and program managers, as well as other stakeholders (i.e. NGOs, development partners), are aware of the Service Delivery Protocol for $P E / E$ for PHC Providers, many were unsure if

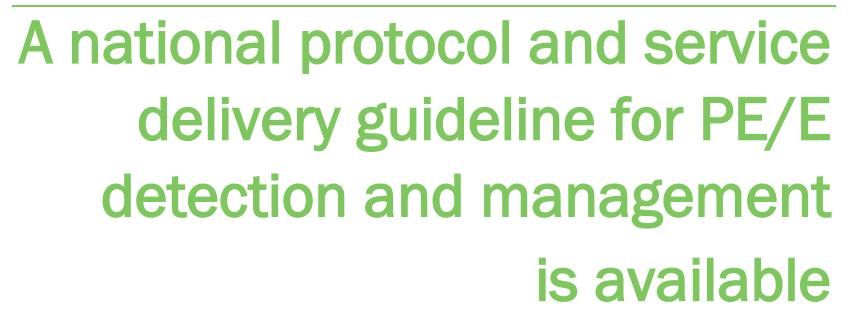
could be labeled a "policy" document. District and sub-district program managers said the government has a policy for reducing maternal and neonatal mortality, along with various initiatives such as promoting institutional delivery, 24/7 normal delivery at UHFWCs, demand-side financing of maternal and neonatal health in selected sub-districts, the Maternal Health Voucher Scheme (DSF-MHVS), and misoprostol distribution through field workers, among others.

The Ending Eclampsia project endeavored, with PAC guidance, to expand PE/E services to PHC facilities, and developed and distributed the Service Delivery Guidelines on PE/E for PHC Providers to all service providers and program managers in the project's four districts and 12 sub-districts.

"I don't know about the government policy. There might be one. I can't tell you about the policy, as I didn't get it yet. I didn't get the policy in my hand so that I don't know about where the policy is being implemented. There is no implementation policy in my district or upazilas."

National program manager and policymaker, MoHFW, Baseline, 2015

"Definitely there is government policy regarding pre-eclampsia and eclampsia, particularly for the secondary and tertiary level facilities. That is national SOP [for maternal health issue], which was already developed in 2014 and endorsed. However, government does not have any policy for the community level. I have heard that a protocol has been developed and tested in some areas."

WHO representative, Baseline, 2015

"As far as I know, the policy is being implemented all over Bangladesh, otherwise reaching the targets of MDGs 4 and 5 were not possible. Of course, we are involved in it, we are providing health care services to all types of patients from national, district, and sub-district health facilities."

National program manager and policymaker, MoHFW, Baseline, 2015 
At endline in 2018, awareness had changed.

"Yes, of course Government has a policy on this matter, and you all are also working as part of this policy that loading dose of magnesium sulphate is to be administered to patients with severe preeclampsia and eclampsia. The policy is to prevent death of both mother and child due to preeclampsia and eclampsia. It said, providers who are working at primary health care facility especially at grassroot level including FWV in FWC, senior staff nurse or nurse in the antenatal unit of UHC and DH are assigned to administer loading dose of magnesium sulphate."

District program manager and policymaker, DGHS, Endline, 2018

“We don't have any policy regarding PE/E management. We have a guideline regarding this. We've supplied this guideline to upazila health complexes and they're working according to that. Doctors and Nurses have been trained and now midwifes have joined with them. Midwifes and nurses are trained to administer a loading dose of magnesium sulphate and refer. Some works are going on accordingly in some places and we'd try to do this in all places."

National deputy program manager, DGHS, Endline, 2018

"I am not aware of any government official policy though I know about the current program being conducted by the Population Council." Sub-district program manager, Endline, 2018

"If we speak officially, there's no such policy. Population Council has worked in some areas, MaMoni has worked in some areas. So, in light of that we've made a service delivery guideline for fieldworkers with the involvement of DGFP, OGSB and other stakeholders. So, we're calling this a policy. But there's no exact policy. But this policy can be further implemented with the involvement of all stakeholders. We are implementing this in our project areas."

NGO stakeholder and implementer, Endline, 2018

\section{Early Diagnosis and Impacts on Maternal Health}

At baseline, most national policymakers, district program managers, and other stakeholders (i.e. NGOs, professional bodies and development partners) stated that early marriage, insufficient ANC service use, poverty, and ignorance contribute to the high levels of PE/E in Bangladesh. At both baseline and endline, many district managers said PE identification is delayed because women do not seek ANC, resulting in negative pregnancy outcomes including maternal and neonatal deaths. Similar statements were made by many sub-district managers at baseline, who opined that lack of ANC and general lack of awareness are the main reasons for maternal and neonatal morbidities and deaths due to PE/E. More than three fourths of informants at baseline mentioned that $\mathrm{PE} / \mathrm{E}$ contributed to premature delivery, miscarriage, stillbirth, liver damage, and death.

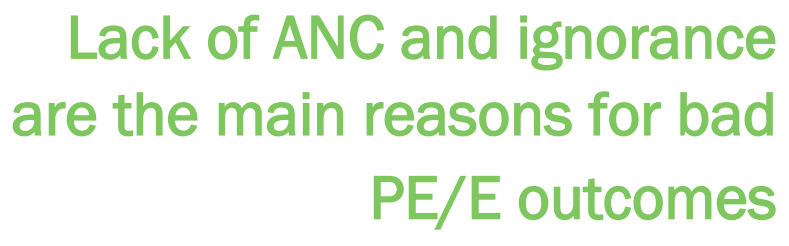

"Due to family barrier [in-laws do not allow], pregnant women do not take antenatal care services properly and do not visit us. They usually come at the last moment, when the disease becomes severe. They [pregnant women and their families] do not have any knowledge about pre-eclampsia and eclampsia. They think it as a simple matter." Sub-district program manager, Baseline, 2015

Similar findings were manifested at endline.

"The detection of pre-eclampsia is delayed because of the lack of early and regular antenatal care check ups. If we can maintain regular antenatal care check ups, bring them to the facility, then identification would be early, and the management would be better and easier, and maternal deaths would have been greatly reduced, as it contributes 20 percent of maternal deaths."

National program manager, DGFP, MoHFW, Endline, 2018 
"We're not managing the antenatal care as it should be. We do not bring all pregnant women for antenatal care check ups. If we could do that, we could have controlled the blood pressure and prevent eclampsia to some extent. Even four antenatal care check ups are not being implemented properly. Both the service providers and the patients are responsible for this. The service providers don't serve full time. We're trying to manage that. Women also have lack of sensitivity and awareness. Even if they feel dizzy, they remain at home. They eat one Paracetamol and stay at home. However, we are trying to improve this situation to avert pregnancy-related complications."

National policymaker, DGFP, Endline, 2018

The need for a protocol and service delivery guidelines for PHC providers was emphasized at baseline, and a draft national protocol for PHC providers was reviewed and revised with an expert committee formed by DGFP. The resulting Service Delivery Protocol and Guidelines for PHC Providers was distributed widely to districts, sub-districts, and PHC facilities. All informants acknowledged receiving the service delivery guidelines, and understood the contents and their relevance.

"I have read the service delivery guideline. As far as I believe, this guideline has no gap. It would be helpful for the primary health care providers to understand how to identify pre-eclampsia and eclampsia patients, how to manage it, and how to refer. We should use and promote this guideline nationwide."

District program manager, DGFP, Endline, 2018

\section{Impact of the Intervention and Task Sharing}

While most informants at baseline supported task sharing with PHC providers (FWVs and SACMOs) to detect, prevent, and manage PE/E, some informants had reservations about Community Skilled Birth Attendants ${ }^{1}$ (CSBAs) along with Community Health Care Providers (CHCPs), a clinic cadre who administer the $\mathrm{MgSO}_{4}$ loading dose.

"We need to think whether permission should be given to primary health care providers for... injection. Primary health care providers can detect pre-eclampsia and eclampsia by measuring blood pressure and urine test. That is simple. After that, they can refer the patients to higher facility. But allowing that level of service providers to administer the injection-we definitely need to think about it, because we have seen abuse. We do not have any mechanism to stop the abuse...doing this, are we causing harm?"

Researcher, icddr,b, Baseline, 2015

For the last two years, progress in all 12 subdistricts' PHC systems, and secondary facilities, enabled PHC provider PE/E detection and management. Policymakers and program managers are pleased with the intervention. At endline, most informants were satisfied with $\mathrm{PHC}$ providers' skills in handling ANC clients with HDP.

In addition, most informants at endline said this intervention would have great impact in reducing maternal deaths if it can be scaled up in other parts of the country.

"I am managing the PE/E program, we have arranged for a separate room called 'ANC Corner'. There are two SACMOs and a nurse here to provide service...to check the pregnant mother's history, check up, measuring blood pressure, urine albumin test, and manage PE/E patients... monitored by me. Population Council's representatives always is there to help us. I am happy to see that our providers are now taking feedbacks from clients and follow up with PE/E survivors."

Sub-district program manager, DGHS, Endline, 2018

1 This intervention does not include CSBAs and therefore these concerns are not related to this study or intervention. 
"I was there at the training program as well. I have ensured the availability of $\mathrm{MgSO}_{4}$, antihypertensives, blood pressure machine, logistics at the emergency departments, ANC, PNC corners and at the labor room. I've checked eclampsia patients personally. I've also been at the field level and I would like to say that magnesium sulphate is a safe drug, which can be administered from any level of health care facility"

"Training that was arranged by the Population Council-for FWV, FWA, SACMO, Nurse, Medical Officer, Consultant-had a wonderful presentation regarding to whom, when and how loading dose of magnesium sulphate would be administered. In my facility, service providers are now identifying $P E / E$ patients, administering loading dose and then, referring them to higher level facilities."

Sub-district program manager, DGHS, 2018

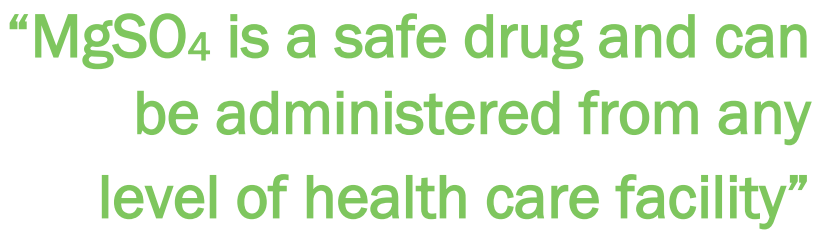

\section{Scaling up of Interventions}

While informants at baseline had diverse views about whether PHC providers could or should administer the modified $\mathrm{MgSO}_{4}$ loading dose, most informants at endline agreed it was necessary to scale up this intervention in other parts of the country because of the effects of maternal and neonatal deaths due to $\mathrm{PE} / \mathrm{E}$. At endline policymakers and program managers said it is essential to implement multiple programs that can address maternal and neonatal deaths, in order to achieve SDGs.

"We say that we made progress in Millennium Development Goals, but still 50 percent of deliveries are...at home, and if there is any problem, they first come to the grass root level health workers such as the Family Welfare Visitor, CSBA, and SACMO. Women usually go to UH\&FWC or Upazila Health Complexes or District Hospitals. If we can make the service providers more aware and train them at the community level, then they can identify pre-eclampsia and eclampsia, administer the loading dose of magnesium sulphate, and refer. Then it will definitely have a good effect and will reduce maternal mortality."

Representative of development partner, Baseline, 2015

Progress has been made in scaling up PE/E interventions. DGFP incorporated PE/E within its next five year operational plan and included a budget for scale up. In addition, DGHS, in collaboration with OGSB, and supported by UNFPA, prepared an "Action Plan for PE/E and PPH," to which other stakeholders contributed, including Ending Eclampsia, and is anticipated to be implemented in 26 districts supported by UNFPA.

"The objective of Ending Eclampsia project in addressing PE/E is undoubtedly promising. We have health providers in the primary level facility, clear management protocol and availability of logistics and commodities. Now this intervention is implemented for few areas for couples of years and we have the learning, we must expand it in larger scale to get the best result in a short period of time otherwise we will not be able to achieve SDGs. As an implementer of the MCH program, I must appreciate the simple ways Population Council showed to address a challenging issue. Now we should not waste any more time and just scale up this intervention in other parts of the country."

National policymaker, MCH program, DGFP, Endline, 2018

"Definitely the program should be scaled up. Eclampsia is still the number two cause of maternal death. If we don't scale up, we can't prevent eclampsia. Definitely it needs to be scaled up in all districts."

Secretary General, OGSB, Endline, 2018 
"So, I think the government should be proactive to expand the program from these four districts to all districts. We OGSB and other NGOs should also come forward. We have to depend on primary health care providers, we can't use doctors, and we don't have that many doctors available for primary health care facilities."

Former President, OGSB

\section{Both DGFP and DGHS need their providers to be trained to provide PE/E services}

"We are ready to scale up the program. We want to expand this program in the entire country. As Population Council have trained them, they've acquired the skill and now they can refer. Even now eclampsia is one of two major causes of death in Bangladesh. So, we definitely want to include this program all of the health complexes in all the districts in Bangladesh. We also have an 'action plan' for pre-eclampsia, eclampsia and postpartum hemorrhage."

Program manager, DGHS, Endline, 2018

"Yes, but I think in Bangladesh, we also have to ask whether the doctors can do it? Because, even the doctors can't do it. I mean...it's easy to give the dose. The first dose is not dangerous, further doses might be. But our problems in Bangladesh is bigger in the community. Our district hospitals are not yet managing eclampsia with doctors there, although...there's no problem with it happening at the community... where we need to target is higher up. We got the medical college hospitals managing it for the most part. They receive the patients and they put them on a reasonable regime, but below that, it's not very functional. So, our target should be at the district hospitals and not yet at the community." Representative of development partner, Endline, 2018

\section{Magnesium Sulphate Supply and Procurement}

The Population Council supplied intervention facilities with $\mathrm{MgSO}_{4}$ with the support of the MacArthur Foundation. DGFP does not supply $\mathrm{PHC}$ facilities with $\mathrm{MgSO}_{4}$, but DGHS is supplying it to UHCs and DHs, along with calcium gluconate

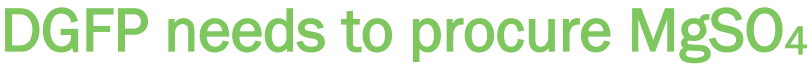
for PHC facilities

(the antidote to $\mathrm{MgSO}_{4}$ toxicity), which remains under-utilized due to the lack of trained providers. Referrals of patients to higher level facilities is SOP. While Ending Eclampsia ensured supplies during the intervention, DGFP program managers are unsure how to proceed when project support concludes.

The government should take responsibility for ensuring $\mathrm{MgSO}_{4}$ availability at every health care facility. According to policymakers, PHCs receive essential medicines and key equipment, including BP machines and urine dipsticks for PE/E detection, directly from the government. It is evident DGFP needs to procure $\mathrm{MgSO}_{4}$ for their PHC facilities.

"Magnesium sulphate, calcium gluconate and anti-hypertensive drugs are not supplied to our Family Planning department. It may be supplied to the health department. We usually prescribe medicines for the pregnant women who come for treatment and have supplied for blood pressure machine, stethoscope, and urine dipsticks." Medical Officer, MCH, DGFP, Baseline, 2015

At endline it was apparent that $\mathrm{MGSO}_{4}$ had still not been procured for PHCs, at least in some places.

"It's still not within our purchasing policy: We are getting supply from Population Council." District program manager, DGFP, Endline, 2018

“We get the supply from Population Council-magnesium sulphate-can't buy it from Family Planning department, and even not supplied through national supply chain. As per my knowledge, it is being purchased in the health department."

District FP manager, DGFP, Endline, 2018 
"Family planning department will purchase magnesium sulphate from now. We have already put this drug in our operational plan and budget is there. We will procure magnesium sulphate very soon."

Policymaker and implementer, DGFP, Endline, 2018

“Currently, we actually do not have stock of magnesium sulphate, we're buying it from CMH. We're procuring magnesium sulphate to supply it to every health complex in each district. We have it in our budget and it's in the process. If we get this, then we can supply this in a while."

Program manager, DGHS, Endline, 2018

“Population Council has been working in four districts, and we've also been working with them at the primary health care level. So, we would like to have a definite plan and estimate from you, the needs for the commodities, so that we can expand it to the entire country. As a part of that plan we can arrange to procure specialized drugs like magnesium sulphate..."

Program Manager, DGFP, Endline, 2018

\section{Health System}

This section describes service providers' knowledge and practices of PE/E management, in addition to logistics and commodities availability, service uptake, quality of care, and program impact. Both the baseline and endline surveys collected data on availability and functionality of logistics and commodities for $\mathrm{PE} / \mathrm{E}$ services, to assess changes due to the intervention, in addition to knowledge assessments.

\section{Facility Readiness}

A facility inventory was conducted at 134 and 136 facilities at baseline and endline, respectively. ANC, PNC, and delivery registers were available at most facilities at baseline and endline, but there was a significant increase in PNC register availability at endline $(95 \%$ to $100 \%, p=0.007)$. Maternity admission registers were only available at 33 percent of facilities at baseline, and at 44 percent at endline (n.s.). Overall findings show significant improvements in availability and functionality of facility structures, commodities, and supplies for MNH services at most facilities. Few facilities, however, had calcium gluconate available at baseline or endline ( $0.7 \%$ and $7.0 \%$, respectively, n.s.).

TABLE 4 Facility readiness, by availability and functionality of MNH indicators

\begin{tabular}{|c|c|c|c|c|c|}
\hline \multirow{2}{*}{ Facility Readiness } & \multicolumn{2}{|c|}{$\begin{array}{l}\text { Baseline } \\
(n=134)\end{array}$} & \multicolumn{2}{|c|}{$\begin{array}{l}\text { Endline } \\
(n=136)\end{array}$} & \multirow[t]{2}{*}{$\begin{array}{c}\text { p- } \\
\text { value }^{a}\end{array}$} \\
\hline & $\mathrm{n}$ & $\%$ & $\mathrm{n}$ & $\%$ & \\
\hline \multicolumn{6}{|l|}{ Availability of MNH registers } \\
\hline ANC and referral register & 134 & 100.0 & 136 & 100.0 & $0.10^{\mathrm{b}}$ \\
\hline Delivery register & 126 & 94.0 & 119 & 88.0 & 0.06 \\
\hline PNC register & 127 & 95.0 & 136 & 100.0 & $0.007^{\mathrm{b}}$ \\
\hline Maternity admission register & 44 & 33.0 & 60 & 44.0 & 0.06 \\
\hline \multicolumn{6}{|l|}{ Availability and functionality of facility structure for MNH services } \\
\hline Clean water supply for 24 hours & 87 & 65.0 & 119 & 88.0 & $<0.001$ \\
\hline 24-hour power supply & 62 & 46.0 & 101 & 74.0 & $<0.001$ \\
\hline Adequate lighting & 78 & 58.0 & 99 & 73.0 & 0.012 \\
\hline Functional autoclave/sterilization instruments & 93 & 70.0 & 108 & 80.0 & 0.06 \\
\hline Infection prevention buckets & 123 & 91.0 & 134 & 99.0 & $0.011^{b}$ \\
\hline \multicolumn{6}{|c|}{ Availability and functionality of commodities and supplies for MNH services } \\
\hline $\begin{array}{l}\text { Functional stethoscopes } \\
\end{array}$ & 120 & 89.0 & 136 & 100.0 & $<0.001^{b}$ \\
\hline Functional sphygmomanometers & 114 & 85.0 & 136 & 100.0 & $<0.001^{b}$ \\
\hline Misoprostol & 87 & 65.0 & 64 & 47.0 & 0.040 \\
\hline
\end{tabular}




\begin{tabular}{|r|c|c|c|c|c|}
\hline Chlorine solution for disinfecting equipment & 110 & 82.0 & 112 & 83.0 & 0.84 \\
\hline Xylocaine/local anesthetics & 34 & 25.0 & 75 & 55.0 & $<0.001$ \\
\hline Syringes and needles & 111 & 82.0 & 129 & 94.0 & 0.002 \\
\hline Normal saline (IV) & 58 & 43.0 & 126 & 92.0 & $<0.001$ \\
\hline IV infusion equipment & 39 & 29.0 & 71 & 52.0 & $<0.001$ \\
\hline Saline stand & 72 & 53.0 & 98 & 72.0 & 0.001 \\
\hline Facility readiness to manage PE/SPE/E at baseline and endline \\
\hline Dipstick on the ward/clinic for testing protein in urine & 14 & 11.0 & 136 & 100.0 & $<0.001^{\mathrm{b}}$ \\
\hline MgSO4 loading dose to manage SPE/E & 4 & 3.0 & 136 & 100.0 & $<0.001^{\mathrm{b}}$ \\
\hline Calcium gluconate for treating MgSO toxicity & 1 & 0.7 & 10 & 7.0 & $0.83^{\mathrm{b}}$ \\
\hline Protocol/guidelines for PE/SPE/PE diagnosis, management & 10 & 8.0 & 136 & 100.0 & $<0.001^{\mathrm{b}}$ \\
\hline
\end{tabular}

a Pearson chi-square test, unless otherwise indicated; ${ }^{\mathrm{b}}$ Fisher's exact test

\section{Provider Knowledge}

Correct provider knowledge is critical for detecting, preventing, and managing HDP. Service providers' knowledge of HDP and PE/SPE/E were assessed in both the baseline $(n=289)$ and endline $(n=328)$ surveys.

Service providers' knowledge was assessed within two domains: 1) their ability to define HDP, as well as PE, SPE, and eclampsia ${ }^{2}$ (Table 5 , following page), and 2) their ability or capacity to diagnose HDP through hypothetical situations (see situations $\mathrm{A}, \mathrm{B}$, and $\mathrm{C}^{3}$, Table 6 , page 17 ). Both sets of questions were asked at baseline and endline. For comparison, service providers were separated into groups of "physicians" and "other service providers" (e.g. FWVs, SACMOs and nurses), and by facility type (PHC or secondary).

Findings indicate significant improvements in provider knowledge, in defining HDP and PE/SPE/E at endline $(p<0.001$ for each, Table 5). Physicians only showed significant knowledge increases in defining SPE, from baseline to endline. FWVs, SACMOs, and nurses increased their knowledge of HDP, PE/SPE/E from baseline to endline ( $p<0.001$ for each). Knowledge of PE was lowest at endline among the four definitions assessed, even though it increased significantly from baseline ( $42 \%$ at baseline vs. $64 \%$ at endline, $p<0.001)$.

Improvements in knowledge occurred among providers at both types of facilities (PHC and referral), as well as among those who had worked at a unit under five years along with those who had worked at a unit more than five years (Table 5). Providers who reported training in $\mathrm{MCH}$ or FP showed significant improvements in knowledge from baseline to endline $(\mathrm{p}<0.001)$ compared to those who reported no $\mathrm{MCH}$ or FP training (Table 5, following page).

2 Hypertension during pregnancy: BP of pregnant women after 20 weeks of pregnancy is 140/90 mmHg or more; Pre-eclampsia: High BP (140/90 mmHg or higher) and presence of albumin in urine determined by dipstick test after 20 weeks of pregnancy; Severe preeclampsia: High BP (140/90 mmHg or higher) + albumin in urine + severe headache, and/or blurred vision, and/or pain in upper abdomen; or diastolic BP $\geq 110 \mathrm{mmHg}$ or systolic $\geq 160 \mathrm{mmHg}$ after two measurements albumin in urine; Eclampsia: hypertension during pregnancy (140/90 $\mathrm{mmHg}$ or greater), albumin in urine, and convulsions during pregnancy

3 Situation A: A pregnant woman was seen in ANC clinic at 12 weeks gestation with BP 160/100mmHg with no proteinuria, what would diagnosis be? Situation B: A pregnant woman was seen in ANC clinic at 30 weeks gestation with BP of 180/115mmHg and proteinuria of $2++$, what would diagnosis be? Situation C: A pregnant woman developed hypertension and significant proteinuria at 30 weeks gestation; one week later, her partner brought her to the clinic with complaints of convulsion, what would diagnosis be? 
Table 5 Correct provider knowledge on definition of HDPs by provider type, facility type, experience and training

\begin{tabular}{|c|c|c|c|c|c|c|c|c|c|c|c|c|}
\hline \multirow{2}{*}{$\begin{array}{l}\text { Provider knowledge } \\
\text { and background } \\
\text { characteristics }\end{array}$} & \multicolumn{3}{|c|}{ Hypertension } & \multicolumn{3}{|c|}{ Pre-Eclampsia } & \multicolumn{3}{|c|}{ Severe Pre-Eclampsia } & \multicolumn{3}{|c|}{ Eclampsia } \\
\hline & $\begin{array}{l}\text { Baseline } \\
(n=289)\end{array}$ & $\begin{array}{l}\text { Endline } \\
(n=328)\end{array}$ & p-value ${ }^{a}$ & $\begin{array}{l}\text { Baseline } \\
(n=289)\end{array}$ & $\begin{array}{l}\text { Endline } \\
(n=328)\end{array}$ & p-value ${ }^{a}$ & $\begin{array}{l}\text { Baseline } \\
(n=289)\end{array}$ & $\begin{array}{l}\text { Endline } \\
(n=328)\end{array}$ & p-value ${ }^{a}$ & $\begin{array}{l}\text { Baseline } \\
(n=289)\end{array}$ & $\begin{array}{l}\text { Endline } \\
(n=328)\end{array}$ & p-value ${ }^{a}$ \\
\hline $\begin{array}{l}\text { Provider correct } \\
\text { knowledge }\end{array}$ & $231(79.9)$ & $324(98.8)$ & $<0.001$ & $120(41.5)$ & $208(63.4)$ & $<0.001$ & $99(34.3)$ & $231(70.4)$ & $<0.001$ & $238(82.4)$ & $307(93.6)$ & $<0.001$ \\
\hline \multicolumn{13}{|l|}{ By provider type, n (\%) } \\
\hline Physician & $62(86.1)$ & $22(100.0)$ & $0.11^{b}$ & $30(41.7)$ & $14(63.6)$ & 0.071 & $38(52.8)$ & $18(81.8)$ & 0.015 & $57(79.2)$ & $20(90.9)$ & 0.21 \\
\hline$n$ & 72 & 22 & & 72 & 22 & & 72 & 22 & & 72 & 22 & \\
\hline FWV/SACMO/nurse & $169(77.9)$ & $302(98.7)$ & $<0.001^{b}$ & $90(41.5)$ & $194(63.4)$ & $<0.001$ & $61(28.1)$ & $213(69.6)$ & $<0.001$ & $181(83.4)$ & $287(94.0)$ & $<0.001$ \\
\hline$n$ & 217 & 306 & & 217 & 306 & & 217 & 306 & & 217 & 306 & \\
\hline \multicolumn{13}{|l|}{ By facility Type, n (\%) } \\
\hline Referral facility & $84.3(86.0)$ & $184(99.5)$ & $<0.001^{b}$ & $44(43.1)$ & $120(64.9)$ & $<0.001$ & $52(50.9)$ & $133(71.9)$ & $<0.001$ & $82(80.4)$ & $174(94.0)$ & $<0.001$ \\
\hline$n$ & 102 & 185 & & 102 & 185 & & 102 & 185 & & 102 & 185 & \\
\hline Primary facility & $145(77.5)$ & $140(97.9)$ & $<0.001^{b}$ & $76(40.6)$ & $88(61.5)$ & $<0.001$ & $47(25.1)$ & $98(68.5)$ & $<0.001$ & $156(83.4)$ & $133(93.0)$ & 0.010 \\
\hline$n$ & 187 & 143 & & 187 & 143 & & 187 & 143 & & 187 & 143 & \\
\hline \multicolumn{13}{|c|}{ By years working in present unit/ward, $n$ (\%) } \\
\hline $1-5$ years & $61(74.4)$ & $127(98.5)$ & $<0.001^{b}$ & $34(41.5)$ & $83(64.4)$ & 0.001 & $33(40.2)$ & $101(78.3)$ & $<0.001$ & $70(85.4)$ & $119(92.3)$ & $<0.001$ \\
\hline$n$ & 82 & 129 & & 82 & 129 & & 82 & 129 & & 82 & 129 & \\
\hline$>5$ years & $86(41.6)$ & $125(62.8)$ & $<0.001$ & $86(41.6)$ & $125(62.8)$ & $<0.001$ & 66 (31.9) & $130(65.3)$ & $<0.001$ & $168(81.2)$ & $188(94.5)$ & $<0.001$ \\
\hline$n$ & 207 & 199 & & 207 & 199 & & 207 & 199 & & 207 & 199 & \\
\hline \multicolumn{13}{|c|}{ Any training on maternal health, FP and/or child health care, $\mathbf{n}(\%)$} \\
\hline Yes & $108(37.3)$ & $324(98.8)$ & $<0.001^{b}$ & $59(20.4)$ & $208(63.4)$ & $<0.001^{b}$ & $47(16.3)$ & $231(70.4)$ & $<0.001^{b}$ & $117(40.5)$ & $307(93.6)$ & $<0.001^{b}$ \\
\hline$n$ & 289 & 328 & & 289 & 328 & & 289 & 328 & & 289 & 328 & \\
\hline
\end{tabular}

a Pearson chi-square test, unless otherwise indicated; b Fisher's exact test; 
From baseline to endline, there were significant increases SPE diagnostic abilities ( $56 \%$ vs. 99\%, $p<0.001$ ), and to a lesser extent, for eclampsia ( $97 \%$ vs. $100 \%, p=0.002$ ), through hypothetical situations (Table 6 ). There was no significant increase in overall correct diagnosis of chronic HTN in pregnancy among providers, in a hypothetical situation, but a greater proportion of physicians as well as FWVs, SACMOs, and nurses made correct diagnoses for chronic HTN in pregnancy and SPE at endline compared to baseline. A greater proportion of FWVs, SACMOs, and nurses made correct diagnoses for eclampsia at endline compared to baseline. All physicians made correct diagnoses for eclampsia at baseline and endline.

Significantly more providers employed at a facility for more than five years made correct diagnoses for all three situations at endline, compared to baseline. There was only a significant change from baseline to endline for SPE diagnosis by service providers who had worked at a facility for one to five years, Nearly all providers who had been worked at a facility for one to five years could correctly diagnose eclampsia at baseline, and all could at endline.

Table 6: Case studies of provider knowledge and diagnosis capacity of chronic hypertension, severe pre-eclampsia and eclampsia, by background characteristics

\begin{tabular}{|c|c|c|c|c|c|c|c|c|c|}
\hline \multirow{3}{*}{$\begin{array}{l}\text { Provider } \\
\text { Knowledge } \\
\text { and Background } \\
\text { Characteristics }\end{array}$} & \multicolumn{9}{|c|}{ Hypothetical Situations } \\
\hline & \multicolumn{3}{|c|}{$\begin{array}{c}\text { Situation A: Pregnant woman } \\
\text { presents at } 12 \text { weeks with BP } \\
160 / 100 \mathrm{mmHg} \text { with no } \\
\text { proteinuria } \\
\text { (Chronic HTN in pregnancy) }\end{array}$} & \multicolumn{3}{|c|}{$\begin{array}{c}\text { Situation B: Pregnant woman } \\
\text { presents at ANC at } 30 \text { weeks } \\
\text { with BP } 180 / 115 \mathrm{mmHg} \\
\text { and proteinuria of } 2++ \\
\text { (Severe PE) }\end{array}$} & \multicolumn{3}{|c|}{$\begin{array}{l}\text { Situation C: Pregnant woman } \\
\text { developed HTN and significant } \\
\text { proteins at } 30 \text { weeks, brought } \\
\text { back a week later } \\
\text { with convulsion (Eclampsia) }\end{array}$} \\
\hline & $\begin{array}{l}\text { Baseline } \\
(n=289)\end{array}$ & $\begin{array}{l}\text { Endline } \\
(n=328)\end{array}$ & $p$-value & $\begin{array}{l}\text { Baseline } \\
(n=289)\end{array}$ & $\begin{array}{l}\text { Endline } \\
(n=328)\end{array}$ & p-value & $\begin{array}{l}\text { Baseline } \\
(n=289)\end{array}$ & $\begin{array}{l}\text { Endline } \\
(n=328)\end{array}$ & p-value \\
\hline $\begin{array}{l}\text { Provider correct } \\
\text { diagnosis }\end{array}$ & $\begin{array}{c}232 \\
(80.0)\end{array}$ & $\begin{array}{c}295 \\
(89.0)\end{array}$ & 0.11 & $\begin{array}{c}162 \\
(56.0)\end{array}$ & $\begin{array}{c}325 \\
(99.0)\end{array}$ & $<0.001$ & $\begin{array}{c}281 \\
(97.0)\end{array}$ & $\begin{array}{c}328 \\
(100.0)\end{array}$ & 0.002 \\
\hline \multicolumn{10}{|l|}{ By provider type, n (\%) } \\
\hline Physician & $\begin{array}{c}62 \\
(86.1)\end{array}$ & $\begin{array}{c}21 \\
(95.5)\end{array}$ & $<0.001$ & $\begin{array}{c}52 \\
(72.2)\end{array}$ & $\begin{array}{c}22 \\
(100.0)\end{array}$ & 0.005 & $\begin{array}{c}72 \\
(100.0)\end{array}$ & $\begin{array}{c}22 \\
(100.0)\end{array}$ & $0.10^{b}$ \\
\hline$n$ & 72 & 22 & & 72 & 22 & & 72 & 22 & \\
\hline FWV/SACMO/nurse & $\begin{array}{c}170 \\
(78.0)\end{array}$ & $\begin{array}{c}274 \\
(89.54)\end{array}$ & $<0.001$ & $\begin{array}{c}110 \\
(50.7)\end{array}$ & $\begin{array}{c}303 \\
(99.0)\end{array}$ & $<0.001$ & $\begin{array}{l}209 \\
(96.3)\end{array}$ & $\begin{array}{c}306 \\
(100.0)\end{array}$ & 0.010 \\
\hline$n$ & 217 & 306 & & 217 & 306 & & 217 & 306 & \\
\hline \multicolumn{10}{|l|}{ By facility Type, n (\%) } \\
\hline Referral & $\begin{array}{c}84 \\
(82.4)\end{array}$ & $\begin{array}{c}172 \\
(92.9)\end{array}$ & $<0.001$ & $\begin{array}{c}74 \\
(72.5)\end{array}$ & $\begin{array}{c}182 \\
(98.4)\end{array}$ & $<0.001$ & $\begin{array}{c}102 \\
(100.0)\end{array}$ & $\begin{array}{c}185 \\
(100.0)\end{array}$ & $0.10^{b}$ \\
\hline$n$ & 102 & 185 & & 102 & 185 & & 102 & 185 & \\
\hline Primary & $\begin{array}{c}148 \\
(79.1)\end{array}$ & $\begin{array}{c}123 \\
(86.0)\end{array}$ & 0.11 & $\begin{array}{c}88 \\
(47.1)\end{array}$ & $\begin{array}{c}143 \\
(100.0)\end{array}$ & $<0.001$ & $\begin{array}{c}179 \\
(95.7)\end{array}$ & $\begin{array}{c}143 \\
(100.0)\end{array}$ & 0.011 \\
\hline$n$ & 187 & 143 & & 187 & 143 & & 187 & 143 & \\
\hline \multicolumn{10}{|c|}{ By years working in present unit/ward, $\mathrm{n}(\%)$} \\
\hline $1-5$ years & $\begin{array}{c}68 \\
(82.9)\end{array}$ & $\begin{array}{c}114 \\
(88.4)\end{array}$ & 0.26 & $\begin{array}{c}49 \\
(59.8)\end{array}$ & $\begin{array}{c}126 \\
(97.7)\end{array}$ & $<0.001$ & $\begin{array}{c}80 \\
(97.6)\end{array}$ & $\begin{array}{c}129 \\
(100.0)\end{array}$ & $0.150^{\mathrm{b}}$ \\
\hline$n$ & 82 & 129 & & 82 & 129 & & 82 & 129 & \\
\hline$>5$ years & $\begin{array}{c}164 \\
(79.2)\end{array}$ & $\begin{array}{c}181 \\
(90.9)\end{array}$ & 0.001 & $\begin{array}{c}113 \\
(54.6)\end{array}$ & $\begin{array}{c}199 \\
(100.0)\end{array}$ & $<0.001^{b}$ & $\begin{array}{c}201 \\
(97.1)\end{array}$ & $\begin{array}{c}199 \\
(100.0)\end{array}$ & $0.03^{b}$ \\
\hline$n$ & 207 & 199 & & 207 & 199 & & 207 & 199 & \\
\hline \multicolumn{10}{|c|}{ Any training on maternal health, FP or child health care, $\mathrm{n}(\%)$} \\
\hline Yes & $\begin{array}{c}114 \\
(39.5)\end{array}$ & $\begin{array}{c}295 \\
(89.9)\end{array}$ & $<0.001^{b}$ & $\begin{array}{c}77 \\
(26.6)\end{array}$ & $\begin{array}{c}325 \\
(99.1)\end{array}$ & $<0.001^{b}$ & $\begin{array}{c}141 \\
(48.8)\end{array}$ & $\begin{array}{c}328 \\
(100.0)\end{array}$ & $<0.001^{b}$ \\
\hline$n$ & 289 & 328 & & 289 & 328 & & 289 & 328 & \\
\hline
\end{tabular}

a Pearson chi-square test, unless otherwise indicated; b Fisher's exact test; 
From baseline to endline there was significant improvement in knowledge among FWVs, SACMOs, and nurses of specific BP for initiation of anti-hypertensive drugs for mild to moderate HDP (43\% vs. $57 \%$, $p=0.002$, Table 7). This improvement was not seen among physicians. Knowledge of precise BP for initiation of anti-hypertensive drugs for severe HDP decreased from eight percent to four percent $(p=0.08)$.

TABLE 7 Service provider knowledge of blood pressure during pregnancy for initiation of anti-hypertensive drugs, at baseline and endline

\begin{tabular}{|c|c|c|c|c|c|}
\hline \multirow{2}{*}{$\begin{array}{l}\text { Knowledge on when to initiate antihypertensive drug } \\
\text { for severity of hypertension }\end{array}$} & \multicolumn{2}{|c|}{ Baseline $(n=289)$} & \multicolumn{2}{|c|}{ Endline $(n=328)$} & \multirow{2}{*}{$\begin{array}{c}\mathrm{p}- \\
\text { value }\end{array}$} \\
\hline & $n$ & $\%$ & $\mathrm{n}$ & $\%$ & \\
\hline $\begin{array}{l}\text { Knew exact BP for initiation of anti-hypertensive } \\
\text { drugs for mild to moderate HDP }\end{array}$ & 161 & 56.0 & 196 & 60.0 & 0.37 \\
\hline $\begin{array}{ll} & \text { Physician }\end{array}$ & 67 & 93.0 & 21 & 95.0 & 0.69 \\
\hline $\mathbf{n}$ & \multicolumn{2}{|c|}{72} & \multicolumn{2}{|c|}{22} & \\
\hline FWV/SACMO/Nurse & 94 & 43.0 & 175 & 57.0 & 0.002 \\
\hline e & \multicolumn{2}{|c|}{217} & \multicolumn{2}{|c|}{306} & \\
\hline $\begin{array}{l}\text { Knew exact BP for initiation of anti-hypertensive } \\
\text { drugs for severe HDP }\end{array}$ & 22 & 8.0 & 14 & 4.0 & 0.08 \\
\hline $\begin{array}{ll} & \text { Physician }\end{array}$ & 18 & 25.0 & 5 & 22.0 & 0.83 \\
\hline $\mathbf{n}$ & \multicolumn{2}{|c|}{72} & \multicolumn{2}{|c|}{22} & \\
\hline FWV/SACMO/Nurse & 4 & 2.0 & 9 & 3.0 & $0.10^{b}$ \\
\hline$n$ & \multicolumn{2}{|c|}{217} & \multicolumn{2}{|c|}{306} & \\
\hline
\end{tabular}

a Pearson chi-square test, unless otherwise indicated; b Fisher's exact test

There was a significant improvement in service providers' correct knowledge of the total loading dose of $\mathrm{MgSO}_{4}$ and its toxicity, from baseline and endline ${ }^{4}-$ a more than fourteen-fold increase $(p<0.001$, Table 8). All service providers knew the correct total loading dose at endline. Provider knowledge of the $\mathrm{MgSO}_{4}$ maintenance dose for SPE/E improved significantly from baseline to endline, but the proportion at endline was lower than expected ( $5 \%$ vs. $22 \%, p=<0.001$ ).

Further knowledge of $\mathrm{MgSO}_{4}$ toxicity was also assessed among service providers. Knowledge of at least one sign or symptom of $\mathrm{MgSO}_{4}$ toxicity, ways to monitor for it, and antidotes significantly increased from baseline to endline, among all providers.

4 The two most commonly used regimens for administering $\mathrm{MgSO}_{4}$ to prevent and treat convulsions in the case of severe $\mathrm{PE} / \mathrm{E}$ are the Zuspan regimen (a loading dose of $4 \mathrm{~g} \mathrm{IV}$, and maintenance dosing of $1 \mathrm{~g} / \mathrm{hr} \mathrm{IV}$ ) and the Pritchard regimen (loading doses of $4 \mathrm{~g}$ IV and $10 \mathrm{~g} \mathrm{IM}$, and maintenance dosing of $5 \mathrm{~g} \mathrm{IM} / 4 \mathrm{hr}$ ). The Pritchard regimen is considered the 'gold standard' using both an intravenous (IV) loading dose including intramuscular (IM) dose and IM maintenance doses.

A modified loading dose called "Dhaka regimen" (10mg IM loading dose and referral to higher facility for further management) has been shown effective in a hospital setting and in primary health care setting (Begum et al 2002 and Shamsuddin et al 2005) and was further tested at primary health care level in Bangladesh (OGSB 2014, Save the Children 2015). The "Dhaka regimen" has been approved by the National Technical Committee (NTC) of DGFP for introduction in the national health system (NTC 2015) and is the regimen used by Ending Eclampsia during this study. 
TABLE 8 Service providers' correct knowledge on total loading and maintenance doses of magnesium sulphate, and its toxicity, at baseline and endline

\begin{tabular}{|c|c|c|c|c|c|}
\hline \multirow{2}{*}{ Knowledge of loading dose of $\mathrm{MgSO}_{4}$} & \multicolumn{2}{|c|}{ Baseline $(n=289)$} & \multicolumn{2}{|c|}{ Endline $(n=328)$} & \multirow{2}{*}{ p- value ${ }^{a}$} \\
\hline & $\mathrm{n}$ & $\%$ & $n$ & $\%$ & \\
\hline $\begin{array}{l}\text { Knew total loading dose of injection of } \mathrm{MgSO}_{4} \\
\text { for SPE/E (Dhaka regime) }\end{array}$ & 21 & 7.0 & 328 & 100.0 & $<0.001^{b}$ \\
\hline $\begin{array}{ll} & \text { Physician }\end{array}$ & 18 & 25.0 & 22 & 100.0 & $<0.001^{b}$ \\
\hline$n$ & 72 & & 22 & & \\
\hline FWV/SACMO/Nurse & 3 & 1.0 & 306 & 100.0 & $<0.001^{b}$ \\
\hline$n$ & 217 & & 306 & & \\
\hline $\begin{array}{l}\text { Knew maintenance dose of } \mathrm{MgSO}_{4} \text { for SPE/E } \\
\text { (Pritchard regime) }\end{array}$ & 14 & 5.0 & 72 & 22.0 & $<0.001$ \\
\hline $\begin{array}{lc} & \text { Physician } \\
\end{array}$ & 14 & 20.0 & 16 & 73.0 & $<0.001$ \\
\hline$n$ & 72 & & 22 & & \\
\hline FWV/SACMO/Nurse & 0 & 0 & 56 & 18.0 & $<0.001^{b}$ \\
\hline$n$ & 217 & & 306 & & \\
\hline $\begin{array}{l}\text { Knew at least one sign or symptom of } \mathrm{MgSO}_{4} \\
\text { toxicity }\end{array}$ & 41 & 14.0 & 121 & 37.0 & $<0.001$ \\
\hline $\begin{array}{ll} & \text { Physician }\end{array}$ & 37 & 51.0 & 21 & 95.0 & $<0.001$ \\
\hline$n$ & 72 & & 22 & & \\
\hline FWV/SACMO/Nurse & 4 & 1.8 & 100 & 33.0 & $<0.001^{b}$ \\
\hline$n$ & 217 & & 306 & & \\
\hline $\begin{array}{l}\text { Knew all ways (depressed respiratory rate, loss } \\
\text { of tendon reflex, decreased urine output) to monitor } \\
\mathrm{MgSO}_{4} \text { toxicity }\end{array}$ & 14 & 5.0 & 40 & 12.0 & 0.001 \\
\hline $\begin{array}{ll} & \text { Physician }\end{array}$ & 13 & 18.0 & 10 & 46.0 & 0.021 \\
\hline$n$ & 72 & & 22 & & \\
\hline FWV/SACMO/Nurse & 1 & 0.01 & 30 & 10.0 & $<0.001^{b}$ \\
\hline$n$ & 217 & & 306 & & \\
\hline $\begin{array}{l}\text { Knew antidote (calcium gluconate) for } \mathrm{MgSO}_{4} \\
\text { toxicity }\end{array}$ & 25 & 9.0 & 77 & 24.0 & $<0.001$ \\
\hline $\begin{array}{lc} & \text { Physician } \\
\end{array}$ & 24 & 33.0 & 17 & 77.0 & $<0.001$ \\
\hline$n$ & 72 & & 22 & & \\
\hline FWV/SACMO/Nurse & 1 & 0.01 & 60 & 19.0 & $<0.001^{b}$ \\
\hline$n$ & 217 & & 306 & & \\
\hline
\end{tabular}

a Pearson chi-square test, unless otherwise indicated; ${ }^{b}$ Fisher's exact test 


\section{Program Effectiveness}

Program effectiveness was measured with various indicators including provider experience in administering loading dose of $\mathrm{MgSO}_{4}$, improvement of in-service provision and referral mechanisms, $\mathrm{PE} / \mathrm{E}$ detection and prevention practice, ANC client experiences, improved quality of care, and service uptake.

Administration of loading dose of $\mathrm{MgSO}_{4}$ significantly increased from baseline to endline (12\% vs. $48 \%$, $p<0.001$, Table 9). This significant increase occurred for physicians as well as for FWVs, SACMOs and nurses. Not all service providers may have had the opportunity to administer a loading dose of $\mathrm{MgSO}_{4}$ due to lack of PE/E clients. At baseline, 91 percent of providers reported that clients or their families were reluctant or refused to take an injection during pregnancy, compared to 17 percent at endline, and only a small number of providers felt confident in administering an $\mathrm{MgSO}_{4}$ injection. At endline, client perceptions had changed due to provider counseling, but a provider challenge was their fear of a community's reaction if a woman with $\mathrm{PE} / \mathrm{E}$ had a negative outcome after receiving $\mathrm{MgSO}_{4}$.

TABLE 9 Service provider experiences administering magnesium sulphate loading dose and operational challenges, at baseline and endline

\begin{tabular}{|c|c|c|c|c|c|}
\hline \multirow{2}{*}{ Practices on loading dose of $\mathrm{MgSO}_{4}$} & \multicolumn{2}{|c|}{ Baseline $(n=289)$} & \multicolumn{2}{|c|}{ Endline $(n=328)$} & \multirow{2}{*}{ p- value ${ }^{a}$} \\
\hline & $\mathrm{n}$ & $\%$ & $\mathrm{n}$ & $\%$ & \\
\hline Had administered loading dose & 35 & 12.0 & 157 & 48.0 & $<0.001$ \\
\hline Physician & 29 & 40.0 & 17 & 77.0 & $<0.001$ \\
\hline$n$ & 72 & & 22 & & \\
\hline FWV/SACMO/Nurse & 6 & 2.8 & 140 & 46.0 & $<0.001$ \\
\hline$n$ & 217 & & 306 & & \\
\hline Confident/skilled in administering loading dose & 132 & 46.0 & 310 & 94.0 & $<0.001$ \\
\hline $\begin{array}{ll}\text { Physician } & \text { Pa }\end{array}$ & 58 & 80.0 & 22 & 100.0 & $0.035^{b}$ \\
\hline$n$ & 72 & & 22 & & \\
\hline FWV/SACMO/Nurse & 74 & 34.0 & 288 & 94.0 & $<0.001$ \\
\hline$n$ & 217 & & 306 & & \\
\hline Operational challenges for loading dose & 129 & 44.6 & 82 & 25.0 & $<0.001$ \\
\hline Physician & 50 & 69.4 & 9 & 40.9 & 0.015 \\
\hline$n$ & 72 & & 22 & & \\
\hline FWV/SACMO/Nurse & 79 & 36.4 & 73 & 23.8 & 0.002 \\
\hline$n$ & 217 & & 306 & & \\
\hline \multicolumn{6}{|l|}{ Type of operational challenge for loading dose** } \\
\hline Reluctance/refusal of patient/family for injection & 118 & 91.0 & 14 & 17.0 & \multirow[b]{2}{*}{$<0.001$} \\
\hline $\begin{array}{r}\text { Provider fear of community reaction to negative } \\
\text { outcome after } \mathrm{MgSO}_{4} \text { use }\end{array}$ & 11 & 9.0 & 68 & 83.0 & \\
\hline$n$ & 129 & & 82 & & \\
\hline $\begin{array}{l}\text { Providers who fear community reaction and felt } \\
\text { confident/skilled administering loading dose }\end{array}$ & 8 & 72.3 & 64 & 94.1 & 0.05 \\
\hline $\begin{array}{ll}\text { By Provider type } \\
\end{array}$ & (11) & & $(68)$ & & \\
\hline Physician & 2 & 66.7 & 7 & 100.0 & $0.30^{b}$ \\
\hline$n$ & 3 & & 7 & & \\
\hline FWV/SACMO/Nurse & 6 & 75.0 & 57 & 93.4 & 0.14 \\
\hline$n$ & 8 & & 61 & & \\
\hline
\end{tabular}


At endline, service providers were asked to report on their service provision after their PE/E training. (These questions were not asked at baseline.) Ninety percent of service providers reported that they were able to identify more hypertensive patients after PE/E training, and 96 percent reported that they could identify ANC patient risk for PE/E or obstetric complications after the training (Table 10). Forty-eight percent of service providers reported subsequent $\mathrm{PE} / \mathrm{E}$ patient management, with significantly more physicians than FWVs, SACMOs, and nurses $(77 \%$ vs. $46 \%, p=0.004)$. Twenty-four percent of patients were managed at $\mathrm{PHC}$ facilities, compared to 76 percent at referral facilities. Physicians managed PE/E at referral facilities only, along with 73 percent of FWVs, SACMOs, and nurses, with 27 percent of FWVs, SACMOs, and nurses managing PE/E at PHC facilities ( $p=0.013$ ).

TABLE 10 Provider self-reports of service provision following intervention, $n(\%)$

\begin{tabular}{|c|c|c|c|c|}
\hline & Total $(n=328)$ & $\begin{array}{l}\text { Physician } \\
(n=22)\end{array}$ & $\begin{array}{l}\text { FWV/SACMO/ } \\
\text { Nurse }(n=306)\end{array}$ & p- value ${ }^{a}$ \\
\hline \multicolumn{5}{|c|}{ Identify more hypertensive patients after received PE/E training? } \\
\hline Yes & $296(90.0)$ & $21(96.0)$ & $275(90.0)$ & $0.60^{b}$ \\
\hline \multicolumn{5}{|c|}{ Identify ANC patient's risk for PE/E or obstetric complications? } \\
\hline Yes & $313(96.0)$ & $21(95.0)$ & $292(94.0)$ & $0.10^{b}$ \\
\hline \multicolumn{5}{|c|}{ PE/E risk factors examined with ANC patients* } \\
\hline Age $<20$ and $>35$ years & $303(92.0)$ & $21(96.0)$ & $282(92.0)$ & 0.57 \\
\hline Primigravida & $151(46.0)$ & $13(59.0)$ & $138(45.0)$ & 0.20 \\
\hline Number of pregnancies $>=4$ times & $209(63.0)$ & $18(82.0)$ & $191(61.0)$ & 0.06 \\
\hline Birth spacing less than 2 years & $110(34.0)$ & $13(59.0)$ & $97(32.0)$ & 0.010 \\
\hline Height $145 \mathrm{~cm}$ or less & $261(80.0)$ & $19(86.0)$ & $242(79.0)$ & 0.41 \\
\hline Previous pregnancy history e & $164(50.0)$ & $3(12.0)$ & $269(88.0)$ & $<0.001^{b}$ \\
\hline Current pregnancy history ${ }^{f}$ & $165(52.0)$ & $2(10.0)$ & $275(90.0)$ & $<0.001^{b}$ \\
\hline \multicolumn{5}{|l|}{ Manage PE/E patient } \\
\hline Yes & $157(47.9)$ & $17(77.3)$ & $140(45.8)$ & 0.004 \\
\hline \multicolumn{5}{|l|}{ Management of PE/E by facility type } \\
\hline Primary facility & $38(24.0)$ & $0(0.0)$ & $38(27.0)$ & \multirow{2}{*}{$0.013^{b}$} \\
\hline Referral facility & $119(76.0)$ & $17(100.0)$ & $102(73.0)$ & \\
\hline$n$ & 157 & 17 & 140 & \\
\hline
\end{tabular}

*Multiple responses; a Pearson chi-square test, unless otherwise indicated; b Fisher's exact test;

e: Hemorrhage at ANC, hemorrhage at PNC, retained placenta, Prolonged labor, HTN/PE/ E in previous pregnancy, Premature baby death, caesarean section history; f: High blood pressure, Diabetes, Heart diseases, Jaundice, Twin Pregnancy, Kidney problem

An important process of service provision improvement was to establish a functional referral mechanism for PE/E patients-from PHC to referral facilities-and use of a project-developed referral slip. Questions about the referral mechanism were only asked at endline. Eighty-one percent of providers thought the Ending Eclampsia referral mechanism was effective. Significantly more providers from referral facilities (85\%) thought the referral mechanism was effective, compared to 76 percent from PHC facilities ( $p=0.034$, Table 11).

Sixty-nine percent of providers used the referral slip to refer patients to a higher facility. Fifty-nine percent of providers referred PE/E patients to higher level facilities $(n=192)$, and of those, 89 percent reported that those patients went to a referral facility for services $(n=170)$, and of those, 94 percent reported that the health care facility solicited their responses or contacted them after their referrals, for the purposes of the study $(n=159)$. 
TABLE 11 Service providers' views of referral mechanisms for PE/SPE/E at endline, $n$ (\%)

\begin{tabular}{|c|c|c|c|c|}
\hline Referral Mechanism & Total $(n=328)$ & Primary $(n=143)$ & Referral $(n=185)$ & p- value \\
\hline \multicolumn{5}{|c|}{ Was Ending Eclampsia referral mechanism effective? } \\
\hline Yes & $267(81.0)$ & $109(76.0)$ & $158(85.0)$ & 0.034 \\
\hline \multicolumn{5}{|c|}{ Used referral slip to refer patients to higher facility? } \\
\hline Yes & $226(69.0)$ & $100(70.0)$ & $126(68.0)$ & \multirow{2}{*}{0.72} \\
\hline No & $102(31.0)$ & $43(30.0)$ & $59(32.0)$ & \\
\hline \multicolumn{5}{|c|}{ Referred PE/E patients to higher facility? } \\
\hline Yes & $192(59.0)$ & $73(51.0)$ & $119(64.0)$ & \multirow{3}{*}{$<0.001$} \\
\hline No & $60(18.0)$ & $16(11.0)$ & $44(24.0)$ & \\
\hline Not found any PE/E patients & $76(23.0)$ & $54(38.0)$ & $22(12.0)$ & \\
\hline$n$ & 328 & 143 & 185 & \\
\hline \multicolumn{5}{|c|}{ Did patients go to higher facility to receive referral services } \\
\hline Yes & $170(89.0)$ & $68(93.0)$ & $102(86.0)$ & \multirow{2}{*}{0.06} \\
\hline No & $22(11.0)$ & $5(7.0)$ & $17(14.0)$ & \\
\hline$n$ & 192 & 73 & 119 & \\
\hline \multicolumn{5}{|c|}{ Has facility collect feedback/contact with patients after referred } \\
\hline Yes & $159(94.0)$ & $68(100.0)$ & $91(89.0)$ & \multirow{2}{*}{$0.003^{b}$} \\
\hline No & $11(6.0)$ & $0(0.0)$ & $11(11.0)$ & \\
\hline$n$ & 170 & 68 & 92 & \\
\hline
\end{tabular}

\section{Provider Practices for Screening and Prevention}

Client-provider interactions (CPIs) were observed at all facilities to assess provider practices for PE risk assessment, screening, and information provided to clients. While one CPI was planned for each provider, in a few cases multiple CPIs of one provider occurred, particularly at endline. Box 1 presents the definitions used for assessing PE risk, screening for $\mathrm{PE}$, and advising on SPE, through composite scores for each. Findings from observation data show that service
Box 1: Definitions Used to Assess Pre-Eclampsia Risk, Detect Pre-Eclampsia, and Advise of Impending Eclampsia During CPI Observations

Assessing Pre-Eclampsia Risk: History of hypertension or high blood pressure, client weight, check for edema (face, hands, legs, ankles), pregnancy order, and client age

Detecting Pre-Eclampsia: Client blood pressure and urinalysis (protein/albumin)

Advising of Severe Pre-Eclampsia Symptoms: Severe headache, blurred vision, high blood pressure, and generalized body swelling (edema) providers poorly measured all three components (assessing PE risk, screening for PE, and advising on SPE) at baseline, but this significantly improved at endline (Table 12). While assessments of PE risk and advice on signs and symptoms significantly improved, these practices were still quite low at endline.

TABLE 12 Provider practices observed during client-provider interactions (for each component)

\begin{tabular}{|l|c|c|c|c|c|}
\hline \multirow{2}{*}{} & \multicolumn{2}{|c|}{ Baseline $(\mathrm{n}=\mathbf{2 6 8})$} & \multicolumn{2}{|c|}{ Endline $(\mathrm{n}=353)$} & $\mathrm{p}$ - value \\
\cline { 2 - 6 } & $\mathrm{n}$ & $\%$ & $\mathrm{n}$ & $\%$ & \\
\hline Assessed risk of PE & 29 & 10.8 & 96 & 27.2 & $<0.001$ \\
\hline Screening for PE & 4 & 1.5 & 218 & 61.8 & $<0.001$ \\
\hline Advise of signs/symptoms of SPE & 9 & 3.4 & 85 & 24.0 & $<0.001$ \\
\hline
\end{tabular}


Five variables (Box 1) measured providers' practices in assessing PE risk, with a summary score for each observation representing the number of variables assessed-0 representing none, 1 representing one risk assessed, up to 5 representing all five risks assessed (The numerals 1 to 4 do not indicate any specific variables, but a score of 5 necessarily includes all five variables).

Observations indicate significant improvement, with service providers for assessing four or five risk factors at endline, compared to three or four at baseline. Further analyses show that the three most frequently assessed factors were birth order (100\%), client weight (82\%), and edema (72\%) at baseline, and birth order (100\%), client weight (88\%), and client age (86\%) at endline, while patient history questions on hypertension were less frequently checked (16\% to $40 \%$, baseline and endline, respectively).

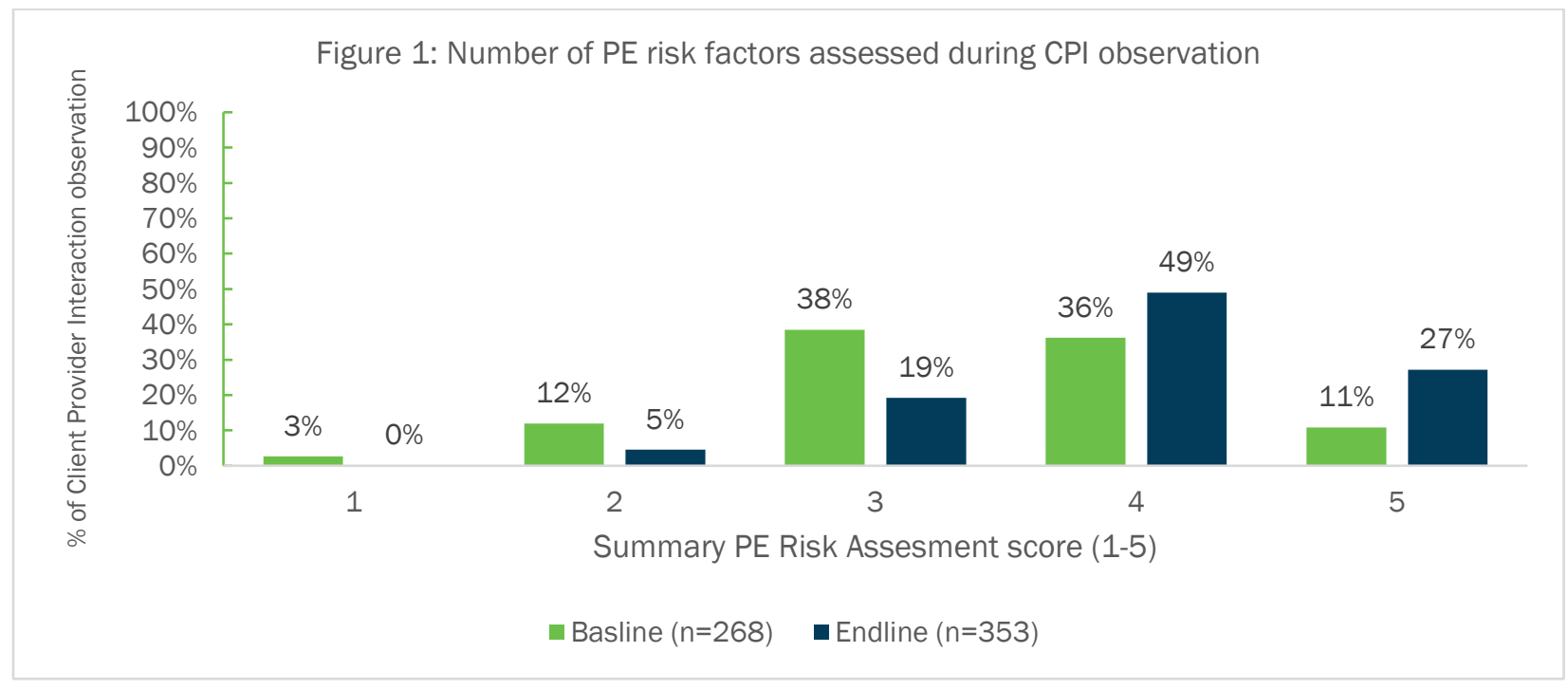

Similar summary scores were generated for each observation of providers screening for PE, which comprises two variables: BP checks and test for albumin in urine. Summary scores generated for each observation show aggregated number of checks for PE screening-1 representing one check and 2 representing two checks. Endline data suggest higher proportions of observed BP checks (98\%) than proteinuria tests (62\%). Baseline data suggest a much lower proportion of proteinuria checks $(2 \%)$ than BP checks (81\%).

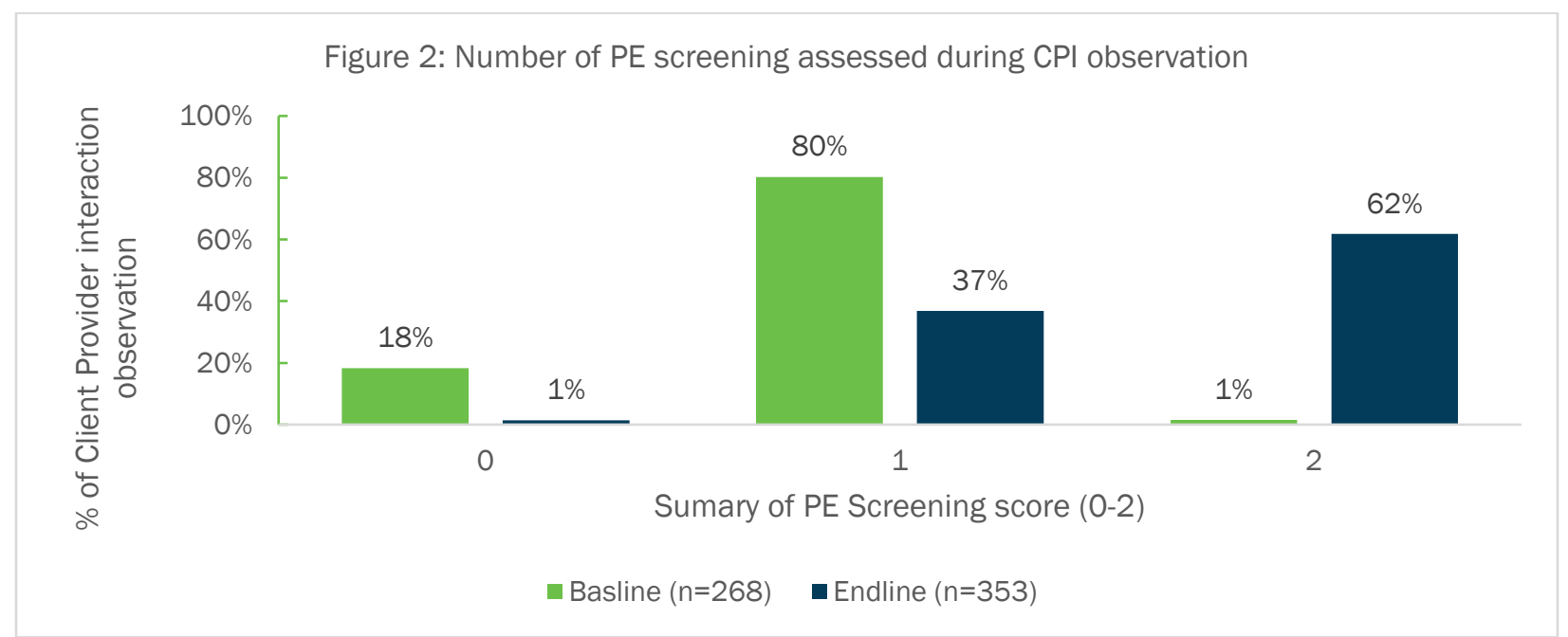

Note: Summary scores generated for each observation shows aggregated number of checks for PE screening (1 representing one check and 2 representing two checks) 
Similar summary scores were generated for each observation to measure provider practice in advising women of PE signs and symptoms, with an aggregated number of signs and symptoms for which advice was provided ( 0 representing none, 1 representing one piece of advice, up to 4 representing advice for all four signs and symptoms; 1 to 3 do not indicate any specific variables; for example, 1 can be any variable and so on, but 4 will be all four variables). Findings indicate significant improvements for provider advice to women of different pregnancy signs and symptoms, particularly two to four signs or symptoms, and a decrease in "no advice" at endline. At baseline most providers either advised on one sign or symptom, or none, and this significantly improved at endline. Edema was the most frequently advised (84\%) sign or symptom at endline, followed by severe headache (63\%), high BP (53\%), and blurred vision (50\%), compared to edema (71\%), severe headache (25\%), high BP (12\%), and blurred vision (12\%) at baseline.

Figure 3: Number of SPE signs/symptom advice assessed during CPI observation

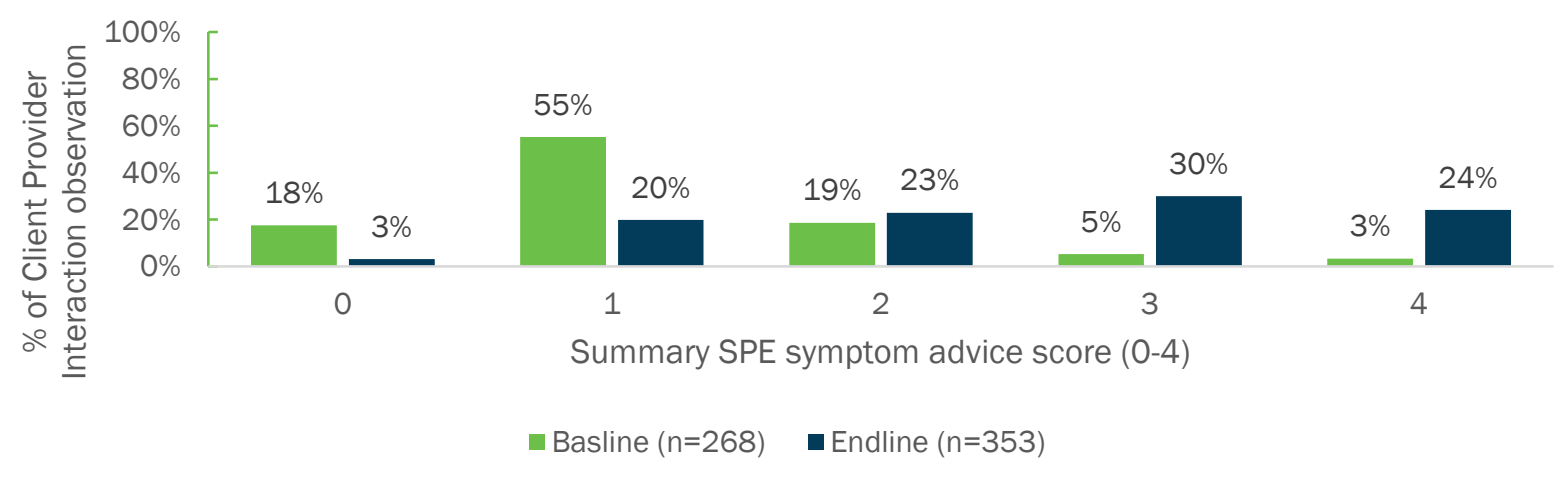

\section{Clients' Experiences at Facilities and Quality of Care}

To determine pregnant women's perceptions of their quality of care, as well as their understanding of those services, the project conducted client exit interviews after CPI observations were complete. There was significant improvement in all nine necessary ANC components except two: abdominal and fetus heartbeat examination. Significantly more clients reported receiving all nine ANC components at endline (1\% at baseline vs. $33 \%$ at endline, $p<0.001$ ).

TABLE 13 Services received during ANC visit, at baseline and endline

\begin{tabular}{|c|c|c|c|c|c|}
\hline \multirow{2}{*}{ ANC service components } & \multicolumn{2}{|c|}{ Baseline $(n=768)$} & \multicolumn{2}{|c|}{ Endline $(n=888)$} & \multirow{2}{*}{ p-value } \\
\hline & $\mathbf{n}$ & $\%$ & $\mathrm{n}$ & $\%$ & \\
\hline Measured weight & 605 & 79.0 & 765 & 86.0 & $<0.001$ \\
\hline Checked BP & 696 & 91.0 & 856 & 96.0 & $<0.001$ \\
\hline Examined abdomen & 616 & 80.0 & 733 & 83.0 & 0.22 \\
\hline Checked for anemia & 562 & 73.0 & 727 & 82.0 & $<0.001$ \\
\hline Listened to baby's heartbeat & 403 & 53.0 & 479 & 54.0 & 0.55 \\
\hline Checked urine for protein and sugar & 34 & 4.0 & 578 & 65.0 & $<0.001$ \\
\hline Told about the progress of pregnancy & 546 & 71.0 & 698 & 79.0 & $<0.001$ \\
\hline Given chance to ask questions & 591 & 77.0 & 754 & 85.0 & $<0.001$ \\
\hline Told to return for another visit & 657 & 86.0 & 863 & 97.0 & $<0.001$ \\
\hline Told about hypertension during pregnancy & - & - & 412 & 46.0 & - \\
\hline Told about PE/E & - & - & 699 & 79.0 & - \\
\hline Proportion of clients received all 9 ANC components & 8 & 1.0 & 292 & 33.0 & $<0.001$ \\
\hline
\end{tabular}

a Pearson chi-square test, unless otherwise indicated; b Fisher's exact test, "-“ not collected at baseline 
Although waiting times increased, clients reported more time with their providers. Although quite high at baseline, significantly more clients reported being satisfied or somewhat satisfied with their services on the day of the survey at endline ( $91 \%$ at baseline vs. $99 \%$ at endline, $p<0.001)$. Ninety-eight percent of clients at endline would recommend a friend attend the same facility for ANC, compared to 89 percent at baseline $(p<0.001)$.

TABLE 14 ANC client experiences at baseline and endline

\begin{tabular}{|c|c|c|c|c|c|c|}
\hline \multirow{2}{*}{ Quality of care Issues } & \multirow{2}{*}{ Categories } & \multicolumn{2}{|c|}{ Baseline $(n=768)$} & \multicolumn{2}{|c|}{ Endline $(n=888)$} & \multirow{2}{*}{$p$ - value ${ }^{a}$} \\
\hline & & $n$ & $\%$ & $n$ & $\%$ & \\
\hline \multirow{2}{*}{$\begin{array}{l}\text { Waiting time before being seen } \\
\text { by service provider (minutes) }\end{array}$} & $<30$ & 651 & 85.0 & 668 & 75.0 & \multirow{2}{*}{$<0.001$} \\
\hline & $>30$ & 117 & 15.0 & 220 & 25.0 & \\
\hline \multirow{2}{*}{ Perception about waiting time } & Too long & 102 & 13.0 & 126 & 14.0 & \multirow{2}{*}{0.85} \\
\hline & Reasonable & 612 & 87.0 & 762 & 86.0 & \\
\hline \multirow{2}{*}{$\begin{array}{l}\text { Time spent with the service } \\
\text { provider (minutes) }\end{array}$} & $<15$ & 664 & 87.0 & 524 & 59.0 & \multirow{2}{*}{$<0.001$} \\
\hline & $>15$ & 104 & 13.0 & 364 & 41.0 & \\
\hline \multirow{3}{*}{$\begin{array}{l}\text { Perception about time spent } \\
\text { with the service provider }\end{array}$} & Too long & 15 & 2.0 & 45 & 5.0 & \multirow{3}{*}{$<0.001$} \\
\hline & Reasonable & 550 & 72.0 & 749 & 84.0 & \\
\hline & Too short & 203 & 26.0 & 94 & 11.0 & \\
\hline \multirow{2}{*}{$\begin{array}{l}\text { Satisfaction of service received } \\
\text { that day }\end{array}$} & $\begin{array}{l}\text { Satisfied, } \\
\text { somewhat satisfied }\end{array}$ & 696 & 91.0 & 872 & 99.0 & \multirow[t]{2}{*}{$<0.001$} \\
\hline & Not satisfied at all & 72 & 9.0 & 16 & 1.0 & \\
\hline $\begin{array}{l}\text { Would recommend a friend } \\
\text { to come to this facility for ANC }\end{array}$ & Yes & 686 & 89.0 & 866 & 98.0 & $<0.001$ \\
\hline
\end{tabular}

Generally, client knowledge of danger signs during pregnancy was low at baseline, and significantly improved at endline $(p<0.001$, Table 15). Although there were significant improvements, there still appear to be gaps in client knowledge, however.

TABLE 15 ANC client knowledge of danger signs during pregnancy

\begin{tabular}{|c|c|c|c|c|c|}
\hline \multirow{2}{*}{ Indicator } & \multicolumn{2}{|c|}{ Baseline $(n=768)$} & \multicolumn{2}{|c|}{ Endline $(n=888)$} & \multirow{2}{*}{ p- value ${ }^{a}$} \\
\hline & $\mathrm{n}$ & $\%$ & $\mathrm{n}$ & $\%$ & \\
\hline \multicolumn{6}{|l|}{ Awareness of danger signs of pregnancy* } \\
\hline Severe Headache & 174 & 23.0 & 502 & 56.0 & $<0.001$ \\
\hline High fever & 119 & 16.0 & 576 & 65.0 & $<0.001$ \\
\hline Upper abdominal pain & 119 & 16.0 & 191 & 22.0 & 0.002 \\
\hline Blurred vision & 36 & 5.0 & 168 & 19.0 & $<0.001$ \\
\hline Excessive bleeding & 267 & 35.0 & 454 & 51.0 & $<0.001$ \\
\hline Convulsion & 163 & 21.0 & 385 & 43.0 & $<0.001$ \\
\hline Obstructive/prolonged labor & 81 & 11.0 & 247 & 28.0 & $<0.001$ \\
\hline Generalized edema & 101 & 13.0 & 118 & 13.0 & 0.934 \\
\hline Absent of fetal movement & 22 & 3.0 & 200 & 23.0 & $<0.001$ \\
\hline \multicolumn{6}{|c|}{ Number of danger signs during pregnancy client knew } \\
\hline None & 134 & 17.0 & 13 & 2.0 & \multirow{4}{*}{$<0.001^{b}$} \\
\hline 1 & 277 & 36.0 & 67 & 7.0 & \\
\hline $2-4$ & 357 & 47.0 & 646 & 73.0 & \\
\hline$>4$ & 0 & 0.0 & 162 & 18.0 & \\
\hline
\end{tabular}




\section{Service Utilization}

Service statistics and project indicators were collected from 136 facilities at baseline (for 3 months), and then monthly for 24 months. At baseline, an average of $16 \mathrm{PE}$, seven severe PE (SPE), and 47 eclampsia patients were seen per month, and those figures significantly increased, to monthly averages of $28 \mathrm{PE}, 19$ SPE, and 65 eclampsia patients during the intervention period $(p<0.001, p<0.001, p<0.001$, respectively, Table 16; appendices $A$ and $B$ show monthly distribution of all 24 months of data and three months of baseline).

Table 16 Uptake of services at baseline and for $\mathbf{2 4}$ months of intervention period, with changes in relevant indicators over time

\begin{tabular}{|c|c|c|c|c|c|c|}
\hline \multirow[t]{2}{*}{ PMP Indicators } & \multicolumn{2}{|c|}{$\begin{array}{c}\text { Baseline } \\
\text { (136 facilities) } \\
\text { October-December '16 } \\
\text { (3 months) }\end{array}$} & \multicolumn{2}{|c|}{$\begin{array}{l}\text { Intervention Period } \\
\text { (136 facilities) } \\
\text { January '17-- } \\
\text { December'18 } \\
\text { (24 months) }\end{array}$} & \multirow[t]{2}{*}{$\begin{array}{c}\% \\
\text { Change }\end{array}$} & \multirow[t]{2}{*}{$\begin{array}{l}\text { Wilcoxon } \\
\text { rank- } \\
\text { sum } \\
\text { statistic } \\
\text { (p-value) }\end{array}$} \\
\hline & Total & Monthly & Total & Monthly & & \\
\hline Women with PE seen at facility & 48 & 16.0 & 664 & 27.7 & $43 \%$ & $<0.001$ \\
\hline Women with SPE seen at facility $n$ & 20 & 6.7 & 445 & 18.5 & $63 \%$ & $<0.001$ \\
\hline Women with eclampsia seen at facility & 142 & 47.3 & 1554 & 64.8 & $28 \%$ & $<0.001$ \\
\hline $\begin{array}{l}\text { Women with SPE/E treated } \\
\text { with } \mathrm{MgSO}_{4}\end{array}$ & 33 & 11.0 & 1,910 & 79.6 & $86 \%$ & $<0.001$ \\
\hline $\mathrm{S}_{\mathrm{C}} \mathrm{C}$ & $20 \%$ & & $96 \%$ & & & - \\
\hline $\begin{array}{l}\text { ANC visits per month } \\
\text { (repeat and new visits) }\end{array}$ & 33,754 & $112,151.3$ & 334,305 & $13,929.4$ & $19 \%$ & $<0.001$ \\
\hline $\begin{array}{l}\text { Women whose BP was measured } \\
\text { during ANC }\end{array}$ & 27,404 & $9,134.7$ & 320,379 & $13,349.1$ & $32 \%$ & $<0.001$ \\
\hline ( & $81 \%$ & & $96 \%$ & & & - \\
\hline $\begin{array}{l}\text { Women whose urine was checked } \\
\text { for albumin at ANC visits }\end{array}$ & 1,943 & 674.7 & 156,527 & $6,521.9$ & $90 \%$ & $<0.001$ \\
\hline e & $6 \%$ & & $47 \%$ & & & - \\
\hline $\begin{array}{l}\text { Pregnant women detected as high risk } \\
\text { during ANC }\end{array}$ & 2,796 & 932 & 77,503 & $3,229.3$ & $71 \%$ & $<0.001$ \\
\hline$\%$ & $8 \%$ & & $23 \%$ & & & - \\
\hline $\begin{array}{l}\text { Pregnant women detected } \\
\text { with high BP during ANC }\end{array}$ & 167 & 55.7 & 3,958 & 164.9 & $66 \%$ & $<0.001$ \\
\hline C & $0.5 \%$ & & $1.2 \%$ & & & - \\
\hline $\begin{array}{l}\text { Mid-level providers trained in PE/E } \\
\text { management, intervention area } \\
\text { (refresher)* }\end{array}$ & 399 & & 217 * & & & \\
\hline $\begin{array}{l}\text { Mid-level providers who can correctly } \\
\text { identify and detect PE } \%\end{array}$ & - & & $93 \%$ & & & \\
\hline $\begin{array}{l}\text { Mid-level providers who can correctly } \\
\text { identify and detect eclampsia } \%\end{array}$ & - & & $94 \%$ & & & \\
\hline $\begin{array}{l}\text { Mid-level providers trained to } \\
\text { competence in appropriate anti- } \\
\text { hypertensive use } \\
\text { (49 pre-intervention, } 44 \text { refresher) } \%\end{array}$ & - & & $100 \%$ & & & \\
\hline $\begin{array}{l}\text { Trained service providers prescribing } \\
\text { anti-hypertensives to control BP } \\
\text { for PE/E patients, intervention area } \\
\text { (refresher)* }\end{array}$ & $\begin{array}{l}49+ \\
44^{*}\end{array}$ & & $\begin{array}{l}5 \text { per } \\
\text { month }\end{array}$ & & & \\
\hline $\begin{array}{l}\text { Pregnant women who attended ANC } \\
\text { aware of } 2+\mathrm{PE} / \mathrm{E} \text { signs/symptoms } \%\end{array}$ & - & & $34 \%$ & & & \\
\hline
\end{tabular}


Rates of PE/SPE/E diagnoses increased during the intervention (Figure 4), particularly for eclampsia.

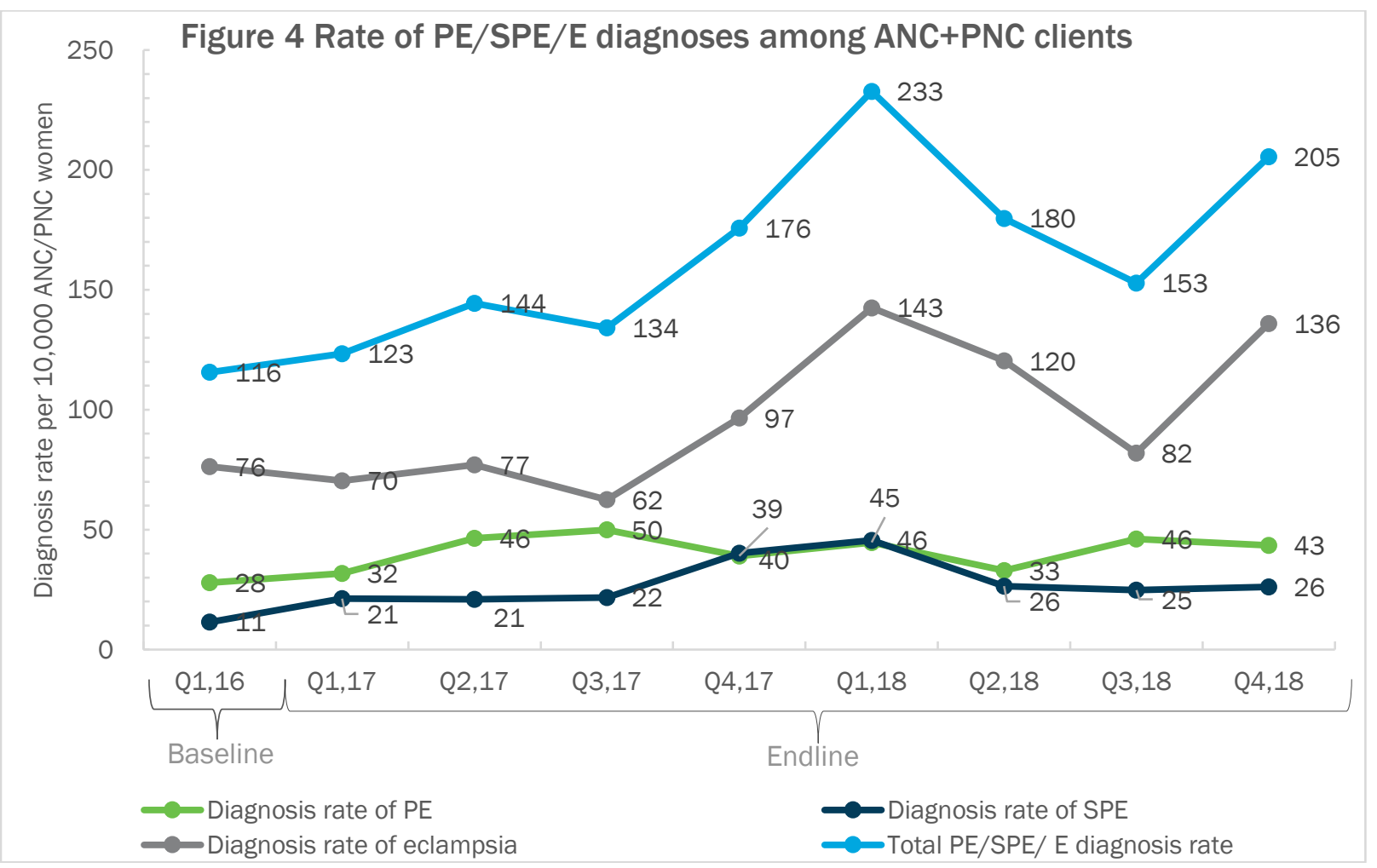

During the baseline period, an average of $11 \mathrm{SPE} / \mathrm{E}$ patients each month were given $\mathrm{MgSO}_{4}$ to prevent and control seizures (20\% of the total seen with SPE/E at the 136 facilities). At endline, there was an eight-fold increase in women given $\mathrm{MgSO}_{4}-80 \mathrm{SPE} / \mathrm{E}$ per month over 24 months, 96 percent of the total SPE/E women seen at the 136 facilities in that time period, Table 16, Figure 5). This increase in treatment of women with SPE/E from baseline to endline was a significant improvement $(p<0.001)$.

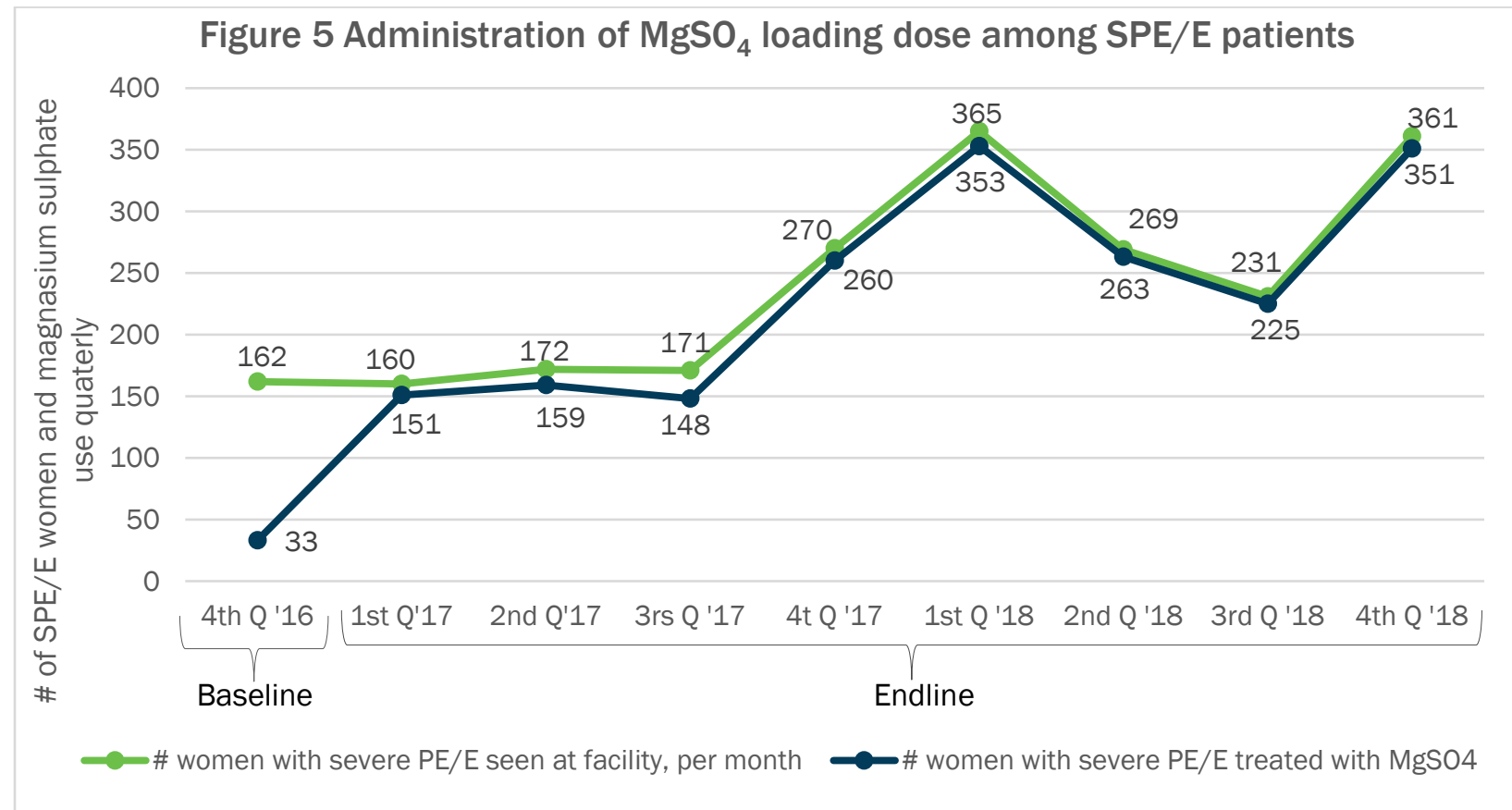


To detect, prevent, and manage $\mathrm{PE} / \mathrm{E}$, correct measurement of $\mathrm{BP}$ and urine testing for albumin is key. The service providers in all intervention facilities were trained for competency in BP measurement, urine testing for albumin, and loading dose administration of $\mathrm{MgSO}_{4}$. While 81 percent of ANC patients had their BP measured at baseline, and six percent of ANC patients' urine was checked for albumin, at endline both BP measurement and albumin testing had significantly increased, to 96 percent and 47 percent, respectively, at endline $(p<0.001$, Table 16$)$.

Screening pregnant women during ANC for high risk factors is extremely important for their successful detection. At baseline screenings by service providers for risk factors in women resulted in only eight percent of pregnant women assessed as high risk, which significantly increased to 23 percent at endline $(p<0.001)$. Detection of high BP among pregnant women also significantly increased, from 56 per month at baseline to 165 per month-a threefold increase at endline $(p<0.001)$. The proportion of high BP detected during ANC among all pregnant women at baseline was 0.5 percent, compared to 1.2 percent at endline $(p<0.001$, Table 16).

\section{Survivors' Experiences}

A different sample of PE/E survivors was interviewed in-depth at baseline and endline. At baseline, $22 \mathrm{PE} / \mathrm{E}$ survivors at a tertiary medical college hospital were interviewed, and at endline 50 survivors from the community who were treated at intervention facilities were interviewed. These PE/E survivors were interviewed to assess their knowledge, attitudes, views, and experiences of PE/E, ANC experiences of PE/E education and screening, the accessibility of essential services and commodities, and their understanding of both the means and courses to appropriate health care.

\section{Antenatal Care}

At baseline, slightly more than two thirds of PE/E survivors had an ANC check up before being admitted to a tertiary hospital, but the quality of their ANC was poor, and they were dissatisfied with the services. Many respondents believed that a fetal ultrasonogram was the major element of ANC.

Although BP was measured in most cases at baseline, a urine albumin test was not done three fourths of the time. Among PE/E survivors interviewed at baseline, about one fifth had elevated BP at an ANC check up and ended up in a tertiary hospital with SPE/E. Almost all of those who attended ANC at baseline reported that their service providers gave no information on possible pregnancy issues or danger signs, nor no explanation of the significance of high BP during pregnancy.

"I got pregnant within three months after my marriage, and did the first check up and ultrasonogram at eighth month from a private clinic. A female doctor checked me and found low blood pressure and suggested for nutritious food, weekly check up, medicine, and assure[d] for normal delivery. I had swollen legs from seventh month and headache, but doctor didn't say anything about it. I thought it is normal in pregnancy. Few weeks later, I had delivery pain with convulsions at midnight. My family took me to a private clinic, they gave me an injection and referred to another hospital and subsequently, they also referred me to Dhaka Medical College hospital."

PE/E survivor, Baseline, 2015

At endline, most PE/E survivors had visited a government health care facility for normal ANC and had received ANC services more than three times, an improvement from baseline. At endline many PE/E survivors had not had an ANC check up until a problem arose, however. Many PE/E survivors who experienced problems including headache, blurred vision, abdominal pain, edema, fever, and leaking membrane visited nearby facilities or unregistered practitioners, and most of these PE/E survivors' high BP 
was diagnosed in the seventh month of pregnancy, and in few cases, just before delivery. This may be due to a delayed ANC check up at a facility or miscalculation of patient gestation.

"I have taken antenatal care services four times. I was taking my first... when I was third month of pregnancy. I was there for a normal check up. In my every check up blood pressure was measured and urine tested. During my first visit, my pressure was normal. My pressure was diagnosed at my seventh month of pregnancy."

PE/E survivor, UH\&FWC, Endline, 2018

"I had never visited any health facility during my pregnancy. I was in Pirganj, at my father's home, four kilometers away from Upazila Health Complex hospital, with the hope to deliver there. One day, I had severe abdominal pain when I was nine months pregnant. During my pregnancy, I used to take sacred water from a traditional healer near my parents' home. I think my abdominal pain was due to the sacred water. I was then taken to the hospital and diagnosed with high blood pressure. The Family Welfare Visitor g[ave] me two injections at my buttocks, and then referred me to Rangpur Medical College Hospital. When the pain went, and I feel better, I went to my parents' home again. I had a normal delivery at my parents' home."

PE/E survivor, Pirganj UHC, Endline, 2018

At baseline most PE/E survivors were unaware of their high BP and did not know about the signs or symptoms of SPE/E. At endline, most PE/E survivors had also not been fully counseled on danger signs in pregnancy. Those who received ANC (about one third of PE/E survivors), said that they knew pregnant women can suffer from hypertension.

"I see a leaflet given by the field workers, but I did not understand what is written there. No one make me understand what is written there."

PE/E survivor, UHC, Endline, 2018

\section{Pregnant Women Seek Care Late}

Community behaviors, particularly for seeking pregnancy care, did not change over time. At baseline, even with problems with high BP, women remained at home, in the hope or belief such a problem was not very serious, or they visited village doctors, Imams, or traditional or spiritual healers. About half of PE/E survivors at endline also did not seek ANC until there was a problem.

"I have no check up myself, while I was pregnant. I...visited the Pachgachi Union Health and Family Welfare Centre at eighth month of my pregnancy, with abdominal pain. The Family Welfare Visitor diagnosed me with high blood pressure. She counseled me about the consequences of high blood pressure and also told me that convulsion can happen. She referred me to Upazila Health Complex for further treatment, but I never went there until I had a convulsion."

PE/E survivor, FWC, Endline, 2018

\section{Magnesium Sulphate Administration}

Information on the timing of $\mathrm{MgSO}_{4}$ administration, survivors' feelings after the injection, and any PNC check ups were collected from $\mathrm{PE} / \mathrm{E}$ survivors at endline. At baseline, no patient had received $\mathrm{MgSO}_{4}$ at a PHC facility, while at endline most PE/E survivors stated they had visited a nearby (i.e. PHC or secondary) facility with problems such as headaches, blurred vision, high BP, abdominal pain, or convulsion, and their service providers had administered a $\mathrm{MgSO}_{4}$ injection. Some survivors even reported visiting the facility for a normal check up when their BP was found to be high, and then providers administered the two injections and referred them to another facility. Most PE/E survivors had no problems or side effects after their loading dose of $\mathrm{MgSO}_{4}$, although a few experienced pain in the injection area for few days. Most patients presented at the referral facility after the loading dose injection from primary or secondary facilities, but a few patients did not follow instructions and remained at home. Most women reported going for PNC at least twice. 
"I went to the Family Welfare Centre to know my blood pressure while I was eight months pregnant. I heard that pressure may be high or low during pregnancy. The apa [FWV] at the facility told me that my blood pressure is too high. She advised me that I need to take two injections now and then, consult with another facility or a physician. Then, she administered two injections at my buttocks and referred to Burirchong Upazila Health Complex." PE/E survivor, UH\&FWC, Endline, 2018

"When I was ninth month[s] pregnant, I went to nearby Family Welfare Centre due to blurring of vision, convulsion, and labor pain. She said I have high blood pressure. She suggested me to go Upazila Health Complex immediately after having some injection. She administered two injections and gave me one tablet. After that I went to Debidwar Upazila Health Complex, where I had a normal delivery. I went for postnatal care services regularly, as my pressure was high, and took medicines, and now, my pressure is normal." $\quad$ PE/E survivor, UH\&FWC, Endline, 2018

A few PE/E survivors did not present to the referral facility, for various reasons including transportation problems, financial issues, or lack of family member for accompaniment.

"At the last stage of my pregnancy I had convulsions and I was brought to nearby Family Welfare Centre. I had delivery pain also. That time, apa administered me two injections [ $\left.\mathrm{MgSO}_{4}\right]$ in my two buttocks and suggested my family to take me to the district hospital. My family refused to go there at that time, because there was no one to accompany me. We said, apa do what you can do, Almighty will save me. After some time, a normal baby boy was born, and my seizures become reduced. I stayed at the Family Welfare Centre for three hours, and there was no repeated convulsion. I have received three postnatal care check ups, the first two in Family Welfare Centre, and the third one in Bhola District Hospital. My pressure is normal now."

PE/E survivor, UH\&FWC, Endline, 2018 


\section{Discussion}

Baseline and intervention data collection were separated by two years, to compare changes in policies, the health system, and community perspectives of PE/E after the introduction of a well-defined PHC intervention to strengthen their providers' capacities. This intervention, with FWVs, SACMOs, and nurses in 136 facilities, also oriented referral facility care providers on referred PE/E patients' care and management.

One policy success was the project's support for the development of the National Protocol and Service Delivery Guidelines on Detection, Prevention and Management of PE/E by PHC Providers, collaboratively developed with DGFP, DGHS, OGSB, and other stakeholders, which was approved for use in the invention facilities-a demonstrable improvement of baseline conditions (Warren et al 2015). This accomplishment likely would not have been realized without Ending Eclampsia's involvement. Any program for PE/E detection, prevention, and management involving PHC providers should have a service delivery protocol in place before intervention implementation. Although national policy dissemination to districts and subdistricts at baseline was sub-optimal (ibid), Ending Eclampsia successfully distributed the service delivery guidelines, as a ready reference, to program managers and service providers in the intervention areas.

The involvement of relevant parties such as DGFP, DGHS, OGSB, Save the Children, Jhpiego, Marie Stopes, as well as others helped increase the significance of addressing PE/E through PHC providers, for SDG achievement through reduced maternal and neonatal deaths. At endline, most policymakers, program managers, and service providers cited improvements in PE/E detection, prevention, and management by PHC providers at intervention facilities, and thought expansion of this intervention to other parts of the country was necessary for reducing maternal and neonatal morbidity and mortality. This supports WHO's and others' recommendations, to address PE/E at the PHC level through task sharing (WHO 2015, 2011).

Training PHC providers in hypertension classification, PE/E, correct BP measurement, albumin urine analysis, pregnancy risk assessment, $\mathrm{MgSO}_{4}$ administration, as well as referrals, were key components of this intervention, in addition to ensuring facility readiness and commodities. Endline findings indicate significant improvements in provider knowledge, skills, and practice (Warren et al 2015). At endline nearly all service providers could correctly diagnose SPE/E in hypothetical situations, with far better results than those in a recent study from Afghanistan in which only 73 percent of SBAs evinced correct knowledge in similar case scenarios (Ansari et al 2019). Although FWVs, SACMOs, and nurses significantly improved their knowledge of BP indicating initiation of anti-hypertensive drugs for mild to moderate HDP, only 57 percent demonstrated this knowledge at endline, while most physicians demonstrated it at both baseline and endline. These findings could be due to the fact that anti-hypertensive drugs were not discussed in training because PHC providers are not allowed to prescribe anti-hypertensive drugs to pregnant women.

Another success of this project is improved knowledge of the loading dose of $\mathrm{MgSO}_{4}$, which increased fourteen-fold from baseline: At endline all providers knew the correct loading dose of $\mathrm{MgSO}_{4}$. Although knowledge among all providers of the maintenance dose of $\mathrm{MgSO}_{4}$ for SPE/E improved significantly at endline $(p<0.001)$, its increase was not as high as expected. The modest increase could be due to the fact training emphasized a modified loading dose of $\mathrm{MgSO}_{4}$, mostly for $\mathrm{PHC}$ providers and referrals, rather than a maintenance dose, which is only supposed to be given at secondary or tertiary facilities. This assumption is substantiated by the finding that more physicians likely to work at secondary facilities demonstrated knowledge of the maintenance dose at endline, compared to FWVs, SACMOs, and nurses.

This intervention's effectiveness was measured according to various indicators, particularly provider experiences in administering a loading dose of $\mathrm{MgSO}_{4}$, improvement of various services as well as PE/E 
detection and management, ANC clients' positive experiences and improved quality of care, improved referral mechanisms, and increased service uptake.

Administration of a loading dose of $\mathrm{MgSO}_{4}$ by all service providers significantly increased $(p<0.001)$ : At endline, nearly half of FWVs, SACMOs, and nurses, along with more than three fourths of physicians, had administered $\mathrm{MgSO}_{4}$. In a similar quasi-experimental study in rural Bangladesh, maternal and neonatal deaths significantly decreased among women who had a loading dose administered locally, compared to those who did not receive a loading dose and only received a referral (Shamsuddin et al 2005).

Not all service providers in this study had a chance to administer a loading dose of $\mathrm{MgSO}_{4}$, due to either a lack of PE/E patients or operational challenges. The most common challenge at baseline was reluctance or refusal of patients and their families for an injection during pregnancy. At endline, the most common challenge was providers' fear of community reactions if patients experienced side effects or died after $\mathrm{MgSO}_{4}$ Administration. These are important barriers to consider if there is an expansion of the intervention, and moreover, both on- and off site digital mentoring for PE/E detection, prevention, and management should be introduced in any expanded program.

Provider practices for detecting and preventing PE/E-by assessing PE risk, detecting it, and advising of impending eclampsia (measured through composite summary score)-was poor at baseline (Warren et al 2015) but significantly improved at endline. Only two percent of all providers frequently measured patients' $\mathrm{BP}$ and proteinuria at baseline, which significantly increased-to 62 percent-at endline, which is another aspect of the intervention's success, and an element that should be promoted within any program that plans to address PE/E through PHC providers, including scale up.

Hodgins et al., in their review articles, conclude that simple interventions during pregnancy, such as PE/E detection, have considerable potential impact on important mortality outcomes (Hodgins et al 2018). Charanthimath et al. concluded, in a study in India, that task sharing with community-based health workers can facilitate early diagnosis of HDP and assist emergency care. Consistent advising by providers on the signs and symptoms of PE/E with every ANC client was not followed even at endline-this needs to be emphasized in provider trainings.

Clients reported improved quality of care at endline, consistent with quality of care findings from BDHS 2017. Ninety-six percent of clients reported BP measurement, consistent with a recent study in Afghanistan (Ansari et al 2019). Sixty-five percent of clients at endline reported urine analysis, yet monitoring data suggest that 47 percent of all service providers measured albumin in urine in the project areas. Providers ascribed low urine testing to uncomfortable environments at clinics and satellite clinics where no toilets are available for urination, along with service provider bias in choosing only risky patients and skipping testing for negative patients in subsequent visits, often because women themselves want to skip it if a previous reports was negative. While testing urine protein for all ANC patients is frequently recommended, experts now believe PE is possible without protein in urine (WHO 2011, NICE 2011, Mayo Clinic 2019, Preeclampsia Foundation 2019). Further research is warranted to determine if urine tests are essential, particularly for community providers in resource-poor settings.

The discrepancy of a greater proportion of clients in exit interviews reporting urine analysis than reported in the monitoring data may indicate a Hawthorne effect, with service providers modifying their behaviors, or even pretending, due to assessment or observation. Monitoring findings also reveal the necessity of proper and consistent documentation of all client information, which is lacking in every facility.

Service delivery statistics show significant improvements in SPE/E treatment as well as BP measurement and urine protein checks during ANC visits. If the PHC PE/E model intervention were to be implemented in all facilities, those findings indicate that PE/SPE/E detection and management would double in two years. 
The proportion of pregnant women detected with high BP during ANC visits also increased. If PHC providers are trained and actively attempt to detect hypertension during ANC, early HDP diagnoses can be increased.

While this intervention is a great success, four percent of SPE/E patients at endline were either not given $\mathrm{MgSO}_{4}$ before referral, or refused an $\mathrm{MgSO}_{4}$ injection. The barriers preventing fulsome administration of $\mathrm{MgSO}_{4}$ should be addressed in any subsequent expansion. In addition, although HDP diagnosis significantly increased, the rate is still low, which indicates the need for more programmatic efforts to motivate service providers for consistent, correct BP measurement and urine testing for albumin during ANC.

There were several limitations to this study, starting with unequal sample sizes of ANC observations, exit client interviews, and PE/E survivor interviews at baseline and endline. To make the study findings robust, different data sources were triangulated, and findings compared. Additionally, service providers' background characteristics at baseline and endline differed, as not all the same providers were interviewed at both data collection points, due to transfers or new postings, which may have contributed to differences in provider knowledge. Training was provided to every provider included in the intervention, however, to equip them with similar knowledge. Finally, a Hawthorne effect may have occurred during observed CPIs, whereby service providers modified their behaviors due to their observation.

Ending Eclampsia employed no rigorous community educational efforts in this Bangladesh program, except a $\mathrm{PE} / \mathrm{E}$ brochure distributed to clients by service providers and field workers. Although a community evaluation was not conducted, the facility assessment shows positive impacts on improved client PE/E knowledge. The trend of late facility attendance during the antenatal period warrants the urgent attention of policymakers and program managers, for strengthened educational efforts within communities and at facilities. In two PE/E survivor cases, an infant death at a referral facility was mistakenly linked with an injection of a loading dose of $\mathrm{MgSO}_{4}$ by the patients and their families. Attention also needs to be paid to patients who abandon the referral process once they receive their $\mathrm{MgSO}_{4}$ injection, which was documented in the intervention areas.

\section{Recommendations}

- The scale up of this PE/E intervention package is widely believed as necessary. It can be accomplished through continued training of service providers, as well as ensuring that referral logistics and commodities are in place. Three days of training on HDP and PE/E for providers, including a one day refresher training after three months following initial training, is recommended.

- On- and off site digital mentoring for PE/E detection, prevention, and monitoring should be introduced in any expanded program. Medical officers-in-charge of PHC providers or district or sub-district obstetric and gynecological (Ob/Gyn) consultants should train their PHC providers. Trainers or mentors should make sure they provide telephone numbers for PHC providers to contact them for further advice.

- Every provider should conduct a PE/E risk assessment for all ANC patients that includes advising of the signs and symptoms of PE/E and other danger signs and symptoms, along with follow up of identified $\mathrm{PE} / \mathrm{E}$ patients.

- Rigorous community educational interventions are recommended for early and regular ANC along with information on danger signs of pregnancy, including HDPs and use of $\mathrm{MgSO}_{4}$ for SPE/E.

- Supervisors should monitor documentation of every patient's relevant information by their PHC providers. 


\section{References}

Abalos E, C Cuesta, AL Grosso, D Chou, L Say. 2013. Global and regional estimates of preeclampsia and eclampsia: a systematic review. European Journal of Obstet Gynecol Reprod Biol 170: 1-7.

Abalos E, L Duley, DW Steyn. 2007. Antihypertensive drug therapy for mild to moderate hypertension during pregnancy. Cochrane Database of Systematic Reviews (1):CD002252.*

Arulkumaran N, L Lightstone. 2013. Severe preeclampsia and hypertensive crises. Best Practices in Research of Clinical Obstet Gynaecol 27: 877-884.

Begum MR, A Begum, E Quadir. 2002. Loading dose versus standard regime of magnesium sulphate in the management of eclampsia: A randomized trial. Journal of Obstetrics \& Gynaecology Research 28: 154-159.

Duley L, DJ Henderson-Smart, S Meher. 2006. Drugs for treatment of very high blood pressure during pregnancy. Cochrane Database of Systematic Reviews (3): CD001449.*

Duley L. 2009. The global impact of pre-eclampsia and eclampsia. Seminars in Perinatology 33(3): 130137.

Mayo Clinic. www.mayoclinic.org/diseases-conditions/preeclampsia/diagnosis-treatment/drc-20355751.

Ansari N, P Manalai, F Maruf, S Currie, J Stekelenburg, J van Roosmalen, YM Kim, H Tappis. 2019. Quality of care in early detection and management of pre-eclampsia/eclampsia in health facilities in Afghanistan. BMC Pregnancy and Childbirth 19: 36.

National Institute for Health and Clinical Excellence (NICE). 2011. Hypertension in pregnancy: The management of hypertensive disorders during pregnancy. NHS, UK.

National Institute of Population Research and Training (NIPORT), International Centre for Diarrhoeal Disease Research, Bangladesh (icddr,b), and MEASURE Evaluation. 2017. Bangladesh Maternal Mortality and Health Care Survey 2016: Preliminary Report. Dhaka and Chapel Hill, NC, USA: NIPORT, icddr,b, and MEASURE Evaluation.

National Institute of Population Research and Training (NIPORT), Mitra and Associates, ICF. 2018. Bangladesh Demographic and Health Survey 2017-18: Key Indicators. Dhaka, Bangladesh, and Rockville, Maryland, USA: NIPORT, Mitra and Associates, ICF.

National Technical Committee (NTC). 2015. Minutes of the 63rd technical committee minute. Dhaka: Directorate General of family Planning (DGFP).

Obstetrical and Gynecological Society of Bangladesh (OGSB), Population Council, EngenderHealth Bangladesh. 2014. Operationalizing the Proposed National Protocol for the Prevention and Management of Severe Pre-Eclampsia and Eclampsia Patients Using Loading Dose of Magnesium Sulphate at Community Level in Bangladesh. Dhaka: Population Council.

Pre-eclampsia Foundation. www.preeclampsia.org/the-news/138-latest-news/637-making-sense-ofpreeclampsia-tests.

Save the Children. 2015. Community-based prevention and management of severe pre-eclampsia/ eclampsia using loading dose of $\mathrm{MgSO}_{4}$. Paper presented at dissemination seminar. Dhaka: Save the Children.

Shamsuddin L et al. 2005. Use of Parenteral Magnesium Sulphate in Eclampsia and Severe Preeclampsia Cases in a Rural set up of Bangladesh. Bangladesh Medical Research Council Bulletin 31(2): 75-82. 
Steegers EA, P von Dadelszen, JJ Duvekot, R Pijnenborg. 2010. Pre-eclampsia. The Lancet 376: 631644.

Hodgins, S, J Tielsch, K Rankin, A Robinson, A Kearns, J Caglia. 2018. A New Look at Care in Pregnancy: Simple, Effective Interventions for Neglected Populations. PLOS ONE.

doi:10.1371/journal.pone.0160562

The Lancet. 2016. Ending preventable stillbirths: Stillbirth rates have fallen from 2000 to 2015 but there are still 2.6 million annual deaths. ScienceDaily. www.sciencedaily.com/releases/2016/01/160118184945.htm.

Charanthimath U, M Vidler, G Katageri et al. 2018. The feasibility of task-sharing the identification, emergency treatment, and referral for women with pre-eclampsia by community health workers in India. Reproductive Health 15(Suppl 1): 101.

Warren, C, S Hossain, RA Nur, K Sultana, K Kirk, A Dempsey. 2015. Landscaping Report on pre-eclampsia and eclampsia in Bangladesh. Washington, DC: Population Council.

World Health Organization. 2007. Maternal mortality in 2005: estimates developed by WHO, UNICEF, UNIFPA and the World Bank. Geneva: World Health Organization.

World Health Organization, UNICEF, UNFPA, World Bank Group, United Nations Population Division. 2015. Trends in maternal mortality: 1990 to 2015: estimates by WHO, UNICEF, UNFPA, The World Bank and the United Nations Population Division. http://apps.who.int/iris/handle/10665/112682

World Health Organization. 2018. Maternal Mortality. www.who.int/news-room/fact-sheets/detail/maternal-mortality.

World Health Organization. 2011. WHO Recommendations for Prevention and Treatment of PreEclampsia and Eclampsia. WHO. Geneva. 


\section{Appendices}

\section{Appendix A: Uptake of services}

for 3 months at baseline, 12 month intervention statistics, and PMP indicators

\begin{tabular}{|c|c|c|c|c|c|c|c|c|c|c|c|c|c|c|c|c|}
\hline PMP Indicators & $\begin{array}{l}\text { Oct } \\
' 16\end{array}$ & $\begin{array}{l}\text { Nov } \\
' 16\end{array}$ & $\begin{array}{l}\text { Dec } \\
' 16\end{array}$ & \begin{tabular}{|c|} 
Baseline \\
total \\
(in 136 \\
facilities) \\
Oct-Dec '16 \\
(3 months) \\
\end{tabular} & $\begin{array}{l}\text { Jan } \\
' 17\end{array}$ & $\begin{array}{l}\text { Feb } \\
' 17\end{array}$ & $\begin{array}{l}\text { Mar } \\
' 17\end{array}$ & $\begin{array}{l}\text { Apr } \\
\text { '17 }\end{array}$ & $\begin{array}{l}\text { May } \\
' 17\end{array}$ & Jun & $\begin{array}{l}\text { Jul } \\
\text { '17 }\end{array}$ & $\begin{array}{l}\text { Aug } \\
' 17\end{array}$ & $\begin{array}{l}\text { Sep } \\
' 17\end{array}$ & $\begin{array}{l}\text { Oct } \\
\text { '17 }\end{array}$ & $\begin{array}{l}\text { Nov } \\
' 17\end{array}$ & $\begin{array}{l}\text { Dec } \\
' 17\end{array}$ \\
\hline Women with pre-eclampsia seen at facility per month $n$ & 8 & 12 & 28 & 48 & 14 & 13 & 29 & 22 & 34 & 26 & 30 & 30 & 41 & 41 & 20 & 19 \\
\hline Women with severe PE seen at facility per month $\quad n$ & 0 & 16 & 4 & 20 & 0 & 29 & 8 & 6 & 13 & 17 & 17 & 6 & 21 & 28 & 16 & 35 \\
\hline Women with eclampsia seen at facility per month & 35 & 38 & 69 & 142 & 66 & 28 & 29 & 36 & 57 & 43 & 44 & 41 & 42 & 49 & 70 & 72 \\
\hline Women with severe $\mathrm{PE} / \mathrm{E}$ treated with $\mathrm{MgSO}_{4}$ & 1 & 9 & 23 & 33 & 59 & 56 & 36 & 40 & 66 & 53 & 58 & 45 & 45 & 74 & 80 & 106 \\
\hline Women with severe PE/E treated with $\mathrm{MgSO}_{4} \quad \%$ & $3 \%$ & $17 \%$ & $32 \%$ & $20 \%$ & $89 \%$ & $98 \%$ & $97 \%$ & $95 \%$ & $94 \%$ & $88 \%$ & $95 \%$ & $96 \%$ & $71 \%$ & $96 \%$ & $93 \%$ & $99 \%$ \\
\hline ANC visits, per month (repeat visits and new) & 11,292 & 12,183 & 10,279 & 33,754 & 11,872 & 12,218 & 12,767 & 13,402 & 13,705 & 11,177 & 15,457 & 14,662 & 13,487 & 15,293 & 14,361 & 11,953 \\
\hline Women whose BP measured in ANC visits & 9,173 & 9,634 & 10,279 & 27,404 & 10,510 & 10,983 & 11,133 & 12,155 & 12,817 & 10,363 & 14,567 & 14,156 & 13,035 & 14,644 & 14,110 & 11,609 \\
\hline ( & $81 \%$ & $79 \%$ & $84 \%$ & $\mathbf{8 1} \%$ & $89 \%$ & $90 \%$ & $87 \%$ & $91 \%$ & $94 \%$ & $93 \%$ & $94 \%$ & $97 \%$ & $97 \%$ & $96 \%$ & $98 \%$ & $97 \%$ \\
\hline Women whose urine checked for albumin at ANC visits $n$ & 312 & 962 & 669 & 1943 & 1,081 & 3,513 & 4,856 & 5,342 & 5,441 & 4,794 & 7,379 & 7,593 & 6,825 & 7,110 & 7,285 & 5,537 \\
\hline$\%$ & $3 \%$ & $8 \%$ & $7 \%$ & $6 \%$ & $9 \%$ & $29 \%$ & $38 \%$ & $40 \%$ & $40 \%$ & $43 \%$ & $48 \%$ & $52 \%$ & $51 \%$ & $46 \%$ & $51 \%$ & $46 \%$ \\
\hline $\begin{array}{l}\text { Pregnant women detected as high risk patients in ANC } \\
\text { visits }\end{array}$ & 702 & 1026 & 1068 & 2796 & 1820 & 2485 & 3056 & 3213 & 3334 & 2753 & 3522 & 3836 & 3851 & 3995 & 4044 & 3126 \\
\hline$\%$ & $6 \%$ & $8 \%$ & $10 \%$ & $8 \%$ & $15 \%$ & $20 \%$ & $24 \%$ & $24 \%$ & $24 \%$ & $25 \%$ & $23 \%$ & $26 \%$ & $29 \%$ & $26 \%$ & $28 \%$ & $26 \%$ \\
\hline $\begin{array}{ll}\begin{array}{l}\text { Pregnant women detected with high BP during ANC } \\
\text { visits }\end{array} & n\end{array}$ & 8 & 90 & 69 & 167 & 75 & 64 & 128 & 152 & 202 & 147 & 237 & 169 & 249 & 182 & 147 & 157 \\
\hline e & 0.001 & 0.007 & 0.007 & 0.005 & 0.006 & 0.005 & 0.010 & 0.011 & 0.015 & 0.013 & 0.015 & 0.012 & 0.018 & 0.012 & 0.010 & 0.013 \\
\hline $\begin{array}{l}\text { Mid-level providers trained on PE/E management } \\
\text { in intervention area }\end{array}$ & & & 399 & 399 & - & - & - & - & - & - & - & - & - & - & - & - \\
\hline $\begin{array}{l}\text { Mid-level providers who can correctly identify and } \\
\text { detect PE }\end{array}$ & - & - & - & - & - & - & - & - & - & - & - & - & - & - & - & - \\
\hline $\begin{array}{l}\text { Mid-level providers who can correctly identify and } \\
\text { detect eclampsia }\end{array}$ & - & - & - & - & - & - & - & - & - & - & - & - & - & - & - & - \\
\hline $\begin{array}{l}\text { Mid-level providers trained (49) to competence } \\
\text { in appropriate anti-hypertensive use }\end{array}$ & - & - & - & - & - & - & - & - & $100 \%$ & & & & & & & \\
\hline $\begin{array}{l}\text { Trained providers prescribing anti-hypertensive drugs } \\
\text { to control BP among PE/E patients at intervention site } n\end{array}$ & - & - & - & $\begin{array}{l}(49+44 \\
\text { trained })\end{array}$ & - & - & - & - & 3 & 4 & 5 & 5 & 6 & 4 & 3 & 5 \\
\hline $\begin{array}{l}\text { Pregnant women who attended ANC aware of 2+ PE/E } \\
\text { signs/symptoms }\end{array}$ & - & - & - & - & - & - & - & - & - & - & - & - & - & - & - & - \\
\hline
\end{tabular}




\section{Appendix B Uptake of services for second year intervention statistics, totals, and PMP indicators}

\begin{tabular}{|c|c|c|c|c|c|c|c|c|c|c|c|c|c|}
\hline PMP Indicators & $\begin{array}{l}\text { Jan } \\
‘ 18\end{array}$ & $\begin{array}{l}\text { Feb } \\
' 18\end{array}$ & $\begin{array}{l}\text { Mar } \\
‘ 18\end{array}$ & $\begin{array}{l}\text { Apr } \\
‘ 18\end{array}$ & $\begin{array}{l}\text { May } \\
' 18\end{array}$ & $\begin{array}{l}\text { Jun } \\
' 18\end{array}$ & $\begin{array}{l}\text { Jul } \\
‘ 18\end{array}$ & $\begin{array}{l}\text { Aug } \\
\text { '18 }\end{array}$ & $\begin{array}{l}\text { Sep } \\
' 18\end{array}$ & $\begin{array}{l}\text { Oct } \\
' 18\end{array}$ & $\begin{array}{l}\text { Nov } \\
' 18\end{array}$ & $\begin{array}{l}\text { Dec } \\
' 18\end{array}$ & $\begin{array}{c}\text { Endline total } \\
\text { (in } 136 \text { facilities) } \\
\text { Jan '17-Dec '18 } \\
\text { (24 months) }\end{array}$ \\
\hline Women with pre-eclampsia seen at facility per month & 28 & 29 & 30 & 29 & 21 & 11 & 31 & 29 & 40 & 42 & 30 & 25 & 664 \\
\hline Women with severe PE seen at facility per month & 31 & 46 & 11 & 26 & 14 & 9 & 16 & 14 & 24 & 21 & 21 & 16 & 445 \\
\hline Women with eclampsia seen at facility per month & 84 & 102 & 91 & 78 & 74 & 68 & 54 & 58 & 65 & 120 & 131 & 52 & 1554 \\
\hline Women with severe $\mathrm{PE} / \mathrm{E}$ treated with $\mathrm{MgSO}_{4}$ & 111 & 140 & 102 & 100 & 86 & 77 & 68 & 71 & 86 & 133 & 150 & 68 & 1910 \\
\hline Women with severe PE/E treated with $\mathrm{MgSO}_{4}$ & $97 \%$ & $95 \%$ & $100 \%$ & $96 \%$ & $98 \%$ & $100 \%$ & $97 \%$ & $99 \%$ & $97 \%$ & $94 \%$ & $99 \%$ & $100 \%$ & $96 \%$ \\
\hline ANC visits, per month (repeat visits and new) & 13,641 & 13,630 & 14,014 & 13,729 & 13,325 & 12,470 & 15,995 & 14,518 & 16,216 & 16,272 & 15,046 & 15,095 & 334,305 \\
\hline Women whose BP measured in ANC visits & 13,169 & 13,222 & 13,664 & 13,391 & 13,054 & 12,267 & 15,788 & 14,218 & 16,048 & 16,083 & 14,650 & 14,743 & 320,379 \\
\hline ( & $97 \%$ & $97 \%$ & $98 \%$ & $98 \%$ & $98 \%$ & $98 \%$ & $99 \%$ & $98 \%$ & $99 \%$ & $99 \%$ & $97 \%$ & $98 \%$ & $96 \%$ \\
\hline Women whose urine checked for albumin at ANC visits & 6,778 & 7,271 & 7,070 & 7,913 & 7,027 & 6,022 & 8,077 & 7,725 & 7,769 & 7,958 & 7,997 & 8,164 & 156,527 \\
\hline & $50 \%$ & $53 \%$ & $50 \%$ & $58 \%$ & $53 \%$ & $48 \%$ & $50 \%$ & $53 \%$ & $48 \%$ & $49 \%$ & $53 \%$ & $54 \%$ & $\mathbf{4 7} \%$ \\
\hline Pregnant women detected as high risk patients in ANC visits & 2,910 & 3,252 & 3,487 & 3,079 & 2,725 & 2,732 & 3,508 & 3,106 & 3,557 & 3,386 & 3,308 & 3,418 & $\mathbf{7 7 , 5 0 3}$ \\
\hline e & $21 \%$ & $24 \%$ & $25 \%$ & $22 \%$ & $20 \%$ & $22 \%$ & $22 \%$ & $21 \%$ & $22 \%$ & $21 \%$ & $22 \%$ & $23 \%$ & $\mathbf{2 3} \%$ \\
\hline Pregnant women detected with high BP during ANC visits & 213 & 197 & 184 & 189 & 139 & 117 & 167 & 180 & 179 & 143 & 147 & 194 & 3,958 \\
\hline$\%$ & 0.016 & 0.014 & 0.013 & 0.014 & 0.010 & 0.009 & 0.010 & 0.012 & 0.011 & 0.009 & 0.010 & 0.013 & 0.012 \\
\hline $\begin{array}{l}\text { Mid-level providers trained on PE/E management in intervention } \\
\text { area (refresher)* }\end{array}$ & $118 *$ & $99 *$ & - & - & - & - & - & - & - & - & - & & 217* \\
\hline Mid-level providers who can correctly identify and detect PE $\%$ & - & - & - & - & - & - & \multicolumn{2}{|c|}{$93 \%$} & - & - & - & & \\
\hline Mid-level providers who can correctly identify and detect $\mathrm{E} \quad \%$ & - & - & - & - & - & - & \multicolumn{2}{|c|}{$94 \%$} & - & - & - & & \\
\hline $\begin{array}{l}\text { Mid-level providers trained (44) to competence in appropriate } \\
\text { anti-hypertensive use (refresher)* }\end{array}$ & $90 \% *$ & & & & & & & - & - & - & - & & \\
\hline \begin{tabular}{|l|} 
Trained service providers prescribing anti-hypertensive drugs to \\
control BP among PE/E patients at intervention site
\end{tabular} & 4 & 8 & 7 & 5 & 4 & 3 & 6 & - & - & - & - & & \\
\hline $\begin{array}{l}\text { Pregnant women who attended ANC aware of 2+ PE/E } \\
\text { signs/symptoms }\end{array}$ & - & - & - & - & - & - & \multicolumn{2}{|c|}{$34 \%$} & - & - & - & & \\
\hline
\end{tabular}

